\title{
O PERÍMETRO BRAQUIAL DA GESTANTE E SUA RELAÇÃO COM O PESO PRÉ-GESTACIONAL E PESO DO RECÉM-NASCIDO
}

\section{ANAMARÍA ELENA RICALDE DE FREIXA}

\author{
Tese de Doutorado \\ apresentada ao Departamento \\ de Saúde Materno - Infantil \\ da Faculdade de Saúde Pública \\ Universidade de São Paulo para \\ obtenção do Grau de Doutor
}

Área de concentração:

Saúde Materno - Infantil

ORIENTADOR : PROF. DR. ARNALDO

AUGUSTO FRANCO DE SIQUEIRA

São Paulo

2000 
Autorizo, exclusivamente para fins acadêmicos e científicos, a reprodução total ou parcial desta tese, por processos fotocopiadores, Assinatura:

Data:

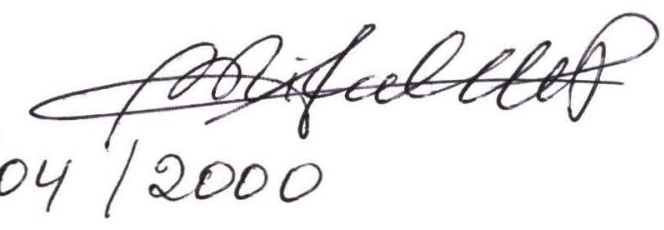

$41121 / 2001($ doc $)$ 
À MMMORIA DA MINHA MÃ̄ 
AO MEU PAI E MEU FILHO PELO CARINHO, INCENTIVO E COMPRHENSÃO EMM TODAS AS FACES DA MINHA VIDA 


\section{AGRADECIMENTOS}

Ao Professor Arnaldo Augusto Franco de Siqueira, pela constante dedicação, incentivo, orientação, apoio incansável e pelas oportunidades que me permitiram crescer profissionalmente.

A Professora Keiko Ogura Buralli, pela amizade e pelo apoio incondicional nas horas dificeis do processo de elaboração da tese.

À Professora Ann Ashworth Hill, pela amizade, pelo apoio e orientação permanentes em todos os momentos do estágio na London School of Hygiene and Tropical Medicine.

À Professora Maria Helena D'Aquino Benicio, pelo carinho dedicado a minha Tese e as oportunas sugestőes para sua elaboração.

À Professora Ana Cristina D'Andreta Tanaka, pela comprensåo, apoio e sugestoes oportunas no processo de elaboração da tese.

Ao Professor Paulo Galo, pelo carinho, incentivo e apoio na elaboraçåo gráfica das propostas da Tese.

Ao Professor José Maria Pacheco, pelo apoio para melhor apresentação dos dados.

À CNPQ, pela concessão de bolsa de Doutorado 
À CAPES, pela bolsa de estudos concedida através do Convênio Bolsas de Estudo no Exterior, que permitiu realizar o estágio na London School of Hygiene and Tropical Medicine.

Aos serviços de pré-natal e neonatologia do Hospital Universitário da USP, pelas facilidades no levantamento de dados.

. Ao centro de saúde escola "Samuel B. Pessoa", pelas facilidades no levantamento de dados.

À Rosi, enfermeira da unidade neonatal do HU-USP, pela dedicação e seriedade no levantamento dos dados.

À Nilson Silva Soares pelo apoio e dedicação na elaboração do banco de dados.

Às secretarias e pessoal assistente do departamento Materno Infantil da FSPUSP, pelo carinho e solidariedade durante estes anos de convivência.

À todos meus amigos que com seu carinho e solidariedade, me apoiaram todos estes anos de trabalho.

E principalmente à todas as gestantes e seus bebes, pela sua colaboração e paciência, permitindo que uma idéia se torne um trabalho realizado. 


\section{RESUMO}

Ricalde AE. O perímetro braquial da gestante e sua relação com o peso pré-gestacional e o peso do recém-nascido. São Paulo; 2000 [Tese de Doutorado - Faculdade de Saúde Pública da USP].

Objetivo. Realizou-se estudo para analisar o perímetro braquial materno como indicador de estado nutricional e como preditor do peso ao nascer.

Métodos. Foram estudados o peso, peso pré-gestacional, estatura, Índice de Massa Corporal, perimetro braquial, idade gestacional e o peso do recémnascido em 350 gestantes e seus recém-nascidos. Análises de correlação e regressão linear simples foram realizadas entre as variáveis estudadas. Testes de sensibilidade e especificidade em diferentes pontos de corte do PB, para predizer baixo peso ao nascer $(<2500 \mathrm{~g})$ e peso inadequado $(<3000 \mathrm{~g})$ foram realizados. Um índice foi calculado utilizando o perimetro braquial e a estatura materna para predizer risco de peso inadequado. Odds ratios e riscos relativos do perimetro braquial e o índice foram comparados. Resultados. O perímetro braquial esta fortemente associado ao peso e índice de massa corporal maternos nos três trimestres da gravidez. $U \mathrm{~m} P B \leq 23,5 \mathrm{~cm}$ pode predizer baixo peso ao nascer (sensibilidade $=45 \%$; especificidade $=83 \%$ e valor preditivo positivo $=14 \%$ ). Um $P B \leq 24,5 \mathrm{~cm}$ pode predizer peso inadequado ao nascer, com $48 \%$ de sensibilidade, $87 \%$ de especificidade e $71 \%$ de valor preditivo positivo. Estes valores ficaram em $39 \% ; 87 \%$ e $65 \%$ respectivamente para 0 indice proposto. Os testes de Odds Ratio e risco relativo, para ambas variáveis 
são semelhantes. Conclusões. O perímetro braquial materno e o índice são preditores do peso inadequado ao nascer. O perímetro braquial pode ser usado no lugar da informação do peso atual ou anterior a gestação, para predizer resultado da gravidez.

Descritores: Antropometria, Gravidez, Peso ao nascer, Saúde Pública 


\section{SUMMARY}

Ricalde $A E$. O perímetro braquial da gestante e sua relação com o peso pré-gestacional e o peso do recém-nascido [Mid upper arm circumference in pregnant women and its relation to pre pregnancy weight and birth weight], São Paulo (BR); 2000, TTese de Doutorado - Faculdade de Saúde Pública da Universidade de São Paulo].

Objective. To analyse mid upper arm circumference as an indicator of nutritional status and predictor of birth weight this study was carried out. Methods. Weight, height, arm circumference, body mass index, mid upper arm circumference, gestational age and birth weight were studied in 350 pregnant women and their newborns. Pearson correlation and regression analyses were studied. Tests of sensitivity and especificity were carried out, using many cohort points to predict low $(<2500)$ and inappropriate $(<3000)$ birth weight. An Index using height an mid upper arm circumference was calculated to predict inappropriate birth weight. The Odds ratio and relative risk of mid upper arm circumference and suggested index were compared. Results. Mid upper arm circumference was strongly correlated with weight and body mass index at any time during pregnancy. Mid upper arm circumference can predict low birth weight at $23,5 \mathrm{~cm}$ level, with high sensitivity $45 \%$; especificity $83 \%$ and a positive predictive value equal to $14 \%$. On the other hand a $<24,5 \mathrm{~cm}$ level of mid upper arm circumference, can be a predictor of inappropriate birth weight 
with $48 \%$ sensitivity, $87 \%$ especificity and $71 \%$ positive predictive value. These results were of $39 \% ; 87 \%$ e $65 \%$ respectively for the suggested index. This index and mid upper arm circumference have similar odds ratios and relatives risks to predict inappropriate birth weight. Conclusions. woman's mid upper arm circumference and suggested index are predictors of inappropriate birth weight. Maternal arm circumference can be used instead of weight or pre pregnancy weight to predict birth weight.

Descriptors: Anthropometry, Pregnancy, Birth weight, Public Health 
ÍNDICE

1 INTRODUÇÃO

1.1 O SIGNIFICADO DA ANTROPOMETRIA NA AVALIAÇÃO DO

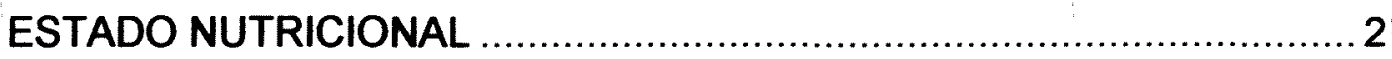

1.2 O SIGNIFICADO DA ANTROPOMETRIA NA GRAVIDEZ ..................

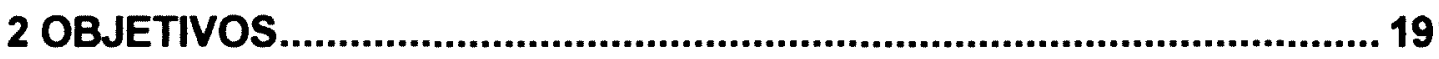

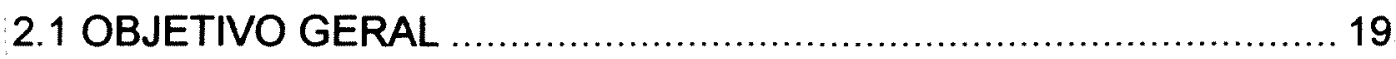

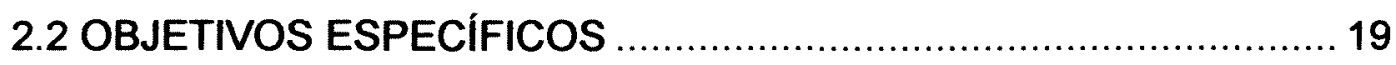

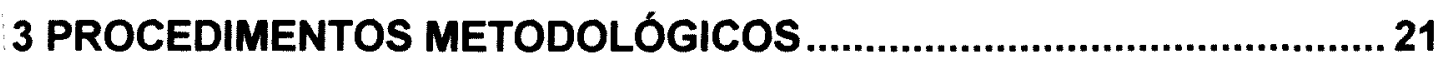

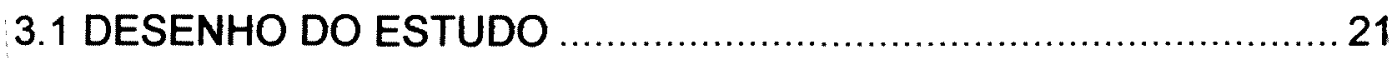

3.2 POPULAÇÃO

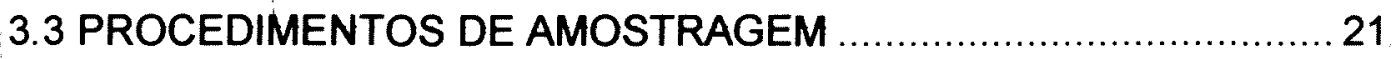

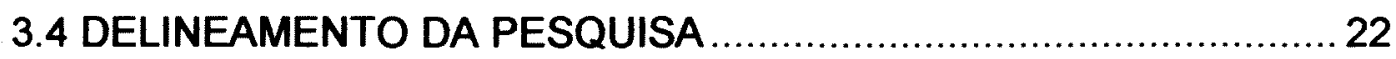

3.5. CRITÉRIOS PARA SELEÇÃO DA POPULAÇÃO DE ESTUDO........22

3.6 TÉCNICAS UTILIZADAS NA COLETA DE DADOS.........................23

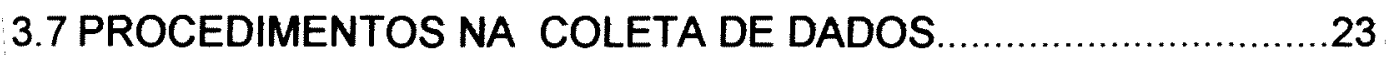

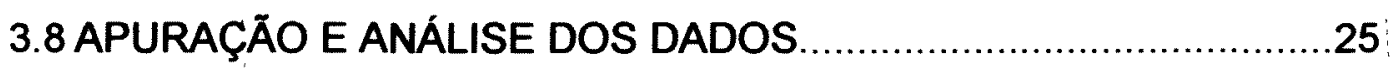

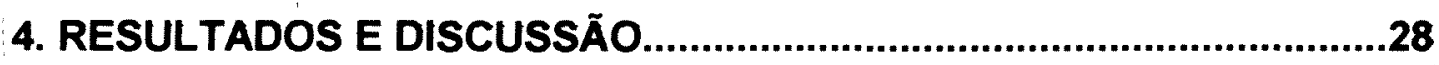

4.1 CARACTERISTICAS GERAIS DA POPULAÇÃO ESTUDADA...........28

4.2 PESO PRÉ-GESTACIONALE GANHO DE PESO ……....................33

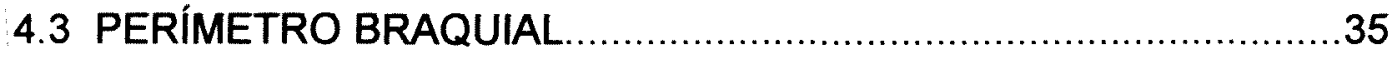

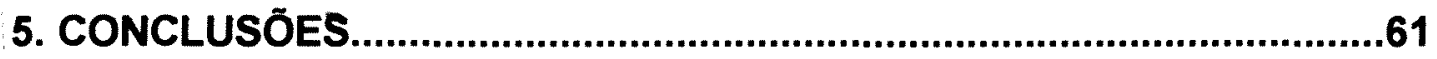

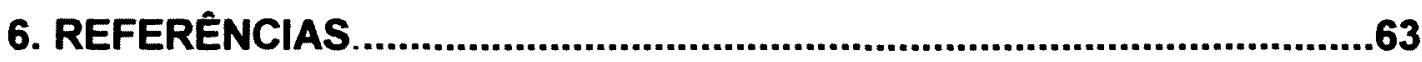

\section{ANEXOS}

Anexo 1 - Lista Dos perimetros, estatura, indice da gestante e o peso do recém nascido. 
Anexo 2 - Índice $<16$ e os correspondentes perímetros braquiais e estatura das gestantes que tiveram recém-nascidos considreados com peso inadequad..

Anexo 3 - Lista do perímetro braquial e a estatura da gestante correspondentes aos diferentes níveis do índice pb/estatura. A11 Anexo 4 - Expressão matemática das curvas para os diferentes niveis do índice pb/estatura da gestante. A12

Anexo 5 - Instrumento de coleta de dados. A13 
INTRODUÇÃO 


\subsection{O SIGNIFICADO DA ANTROPOMETRIA NA AVALIAÇÃO DO ESTADO NUTRICIONAL}

As medidas do corpo humano são estudadas pela técnica da antropometria, largamente utilizada para a avaliação do estado nutricional dos individuos e para planejar a participação destes em programas de intervenção. Em geral, a antropometria não proporciona a informação etiológica específica sobre o transtorno individual de saúde ou nutrição (WHO 1995), mas pode ajudar a determinar que populações deveriam ser monitorizadas e priorizadas pelos diferentes programas de intervenção nestas áreas, ao mesmo tempo em que pode determinar a qualidade da resposta dos indivíduos a estes programas.

O uso da antropometria é o primeiro passo dentro de uma série de provas especificas que conduzem a uma intervenção eficaz (OMS 1969). Existem dois tipos de situações nas quais a avaliação antropométrica pode ser utilizada, e estas são:

1) As situações de emergência e

2) As situações onde uma intervenção está sendo planejada

Portanto, a situação determinará quais medições e técnicas antropométricas deverão ser seguidas. As situaçōes de emergência incluem situações de fome ou de campos de refugiados. A avaliação nesta situação, usando a antropometria, identificará os individuos em grande risco, e então estes terão prioridade para receber ajuda. Nestas condições, as técnicas de rasteio deverão 
ser as mais fáceis de executar, pois geralmente tais situações envolvem grandes grupos de pessoas, o que inviabiliza uma avaliação longitudinal, e então as medições antropométricas são realizadas em apenas uma única entrevista com os indivíduos, para determinar a necessidade de intervenção (WHO 1995; BENDER e REMAUCUS 1998).

A informação da situação nutricional é usualmente parte de um sistema de vigilância utilizado para alertar aos gestores dos programas de saúde, sobre a existência de um problema. Geralmente, a situação que o sistema trata de identificar é a da desnutrição aguda, principalmente em crianças. Para o grupo das gestantes deve importar a condição crônica de uma situação nutricional desfavorável, já que esta condição repercute mais do que a condição aguda no resultado da gravidez. Em conseqüência, a eleição do melhor indicador antropométrico depende dos propósitos para os quais o indicador será utilizado (HABICHT 1990).

No caso da desnutrição em curso ou aguda em crianças, o melhor indicador a ser usado é o peso / altura. Uma prevalência elevada de baixo peso para a estatura indica acontecimentos atuais ou recentes graves, por exemplo, fome ou epidemias de doenças infecciosas como diarréia, sarampo (WHO 1995).

No adulto, a medida do perímetro braquial (PB), o perímetro muscular do braço (PMB) e o índice creatinina-estatutra, podem refletir o aumento ou perda das reservas de energia e proteína, inclusive com maior precisão do que o peso 
corporal (WHO 1995). Em geral, nos adultos, são avaliadas duas situações: o sobrepeso e a magreza, e para tal efeito é utilizado o Índice de Massa Corporal (IMC), que estuda a relação do peso à altura do indivíduo. O IMC apresenta-se como um bom indicador do excesso de gordura, tanto em homens como em mulheres (WHO 1995). Quanto aos adultos magros, recentemente se definiram os graus de peso insuficiente como "carência energética crônica (FERRO-LUZZI e col. 1992), determinada na base do IMC em níveis especificos, assim a magreza é classificada em leve (IMC de 17,0 a $18,49 \mathrm{~kg} / \mathrm{m}^{2}$ ), moderada (IMC de 16,0 a $16,99 \mathrm{~kg} / \mathrm{m}^{2}$ ) e grave (IMC menor de $16 \mathrm{~kg} / \mathrm{m}^{2}$ ).

Nas gestantes, o critério de utilidade das medições antropometricas maternas esta relacionado com a associação do indicador e o resultado adverso da gestação, principalmente, no que diz respeito ao recém-nascido pequeno para a idade gestacional, ou seja com retardo de crescimento intra-uterino. Vários fatores foram considerados causa das diversas formas de retardo de crescimento intra-uterino (KRAMER 1987; NAEYE 1979), no entanto, a desnutrição materna foi descrita como uma causa associada ao retardo de crescimento intra-uterino do tipo simétrico que é potencialmente a mais prejudicial para o feto ( WINICK 1976).

Em relação aos métodos antropométricos para detectar a mulher grávida em risco de dar a luz um recém-nascido de baixo peso, foram recomendados principalmente o ganho de peso durante a gravidez, altura uterina, perímetro braquial, ganho de peso como percentagem do padrão de peso/altura, peso 
pré-gestacional, peso/altura nos diferentes períodos da gravidez. Nos países em desenvolvimento, onde os recursos para atendimento à saúde da comunidade são limitados, existe a preocupação do uso de tecnologia mais simples, de baixo custo, boa reprodutibilidade e treinamento simples para sua aplicação. A medida do Perimetro Braquial satisfaz estas condições, pelo que tem sido utilizada na monitoragem do estado nutricional de crianças, e atualmente é recomendado seu uso em mulheres (ANDERSON 1989; KRASOVEC 1989; LECHTIG 1976; SHAH 1982).

Na situação de não emergência, a avaliação antropometrica é feita por dois motivos: quando as pessoas precisam ser identificadas para participar de programas de início imediato; ou para identificar as famílias de alto risco. Neste caso, a intervenção planejada pode não ter como foco direto a questão nutricional, mas pode estar desenhada para mudar alguns comportamentos dos usuários. Desta forma, a antropometria pode ajudar a identificar os participantes que estão em risco por longo tempo.

Entre as crianças, a condição de interesse dependerá do tipo de programa a ser implementado. Se o programa está desenhado para ter um efeito de curto prazo, a prevalência dos desproporcionados (wasting) ou dos que estão com baixo peso deve ser avaliada, e neste caso o indicador a ser utilizado é o peso por altura (BENDER e REMAUCUS 1998). Para os programas a longo prazo, o estudo dos proporcionados (stunting) é o mais apropriado, neste caso a altura por idade é o indicador usado para detectar a 
condição de má nutrição crônica. Quanto as gestantes, é importante reconhecer a situação nutricional prévia à gestação, pois esta condição é determinante para o resultado da gravidez (BULL WHO 1995), neste caso é utilizada a medida do peso pré-gestacional. Ultimamente tem sido recomendado o uso do perímetro braquial para avaliar a situação nutricional prévia à gestação (SHAH 1991; OLUKOYA e GIWA 1991; RICALDE 1994).

Como já foi mencionado anteriormente, a avaliação do estado nutricional pode ser realizada em apenas uma ocasião, quando uma visão rápida dos indivíduos é requerida. Esta informação pode ser útil em dois tipos de situações:

1. Crise de alimentos - nesta situação é esperado que o estado nutricional das pessoas seja seriamente afetado. Então a avaliação antropométrica de uma só vez nesta situação proporcionará um resumo imediato da dimensão do problema. A condição que é medida nestas ocasiões é a de uma desnutrição aguda.

2. Planejamentos a longo prazo - A avaliação antropométrica em uma só ocasião pode também ser utilizada para decidir que tipos de programas seriam necessários numa determinada área, então é importante ter a informação sobre a população que está vivendo nessa área.

As mediçōes antropométricas da população podem ser parte das informações que proporcionam subsidios quanto aos tipos de programas de intervenção que seriam necessários para melhorar a situação de saúde. Apesar de existirem princípios comuns que orientam o uso da antropometria nos 
indivíduos, é preciso estabelecer uma distinção clara entre os indivíduos das regiōes mais desenvolvidas e as menos desenvolvidas (WHO 1995).

\subsection{O SIGNIFICADO DA ANTROPOMETRIA NA GRAVIDEZ}

Nos paises em desenvolvimento, a principal causa de baixo peso ao nascer continua sendo o Retardo de Crescimento Intra-uterino (RCIU), devido, principalmente, à má nutrição materna (LECHTIG 1988; ARISOY e SARMAN 1995), que tem sido bastante estudada e avaliada inclusive através de métodos antropométricos, entre outros.

No Brasil, o estado nutricional das mulheres em idade fértil tem melhorado nas ultimas décadas (NUPENS/USP 1997) em todo o país, exceto nas áreas rurais da região Nordeste, onde a prevalência do déficit ponderal (IMC $<18,5 \mathrm{~kg} / \mathrm{m}^{2}$ ) continua sendo maior do que no restante do país.

Independentemente das causas, o resultado de uma gravidez, em termos do peso do recém nascido, continua sendo uma preocupação em saúde pública, em todos os paises do mundo, a preocupação se dá pelo fato de que a prevalência de baixo peso ao nascer (BPN) não tem diminuído consideravelmente ao longo do tempo (KRAMER 1987), e sobretudo, porque as repercussões deste na morbimortalidade infantil continuam sendo importantes (BULL. WHO 1993; WILEY 1994). 
Alguns estudos (OTT 1993; PALO e ERKKOLA 1993) têm demonstrado que a mortalidade perinatal é mais comum nos prematuros pequenos para a idade gestacional (PIG com RCIU) do que entre os prematuros adequados (AIG).

As estimativas globais das médias de peso ao nascer e a prevalência de baixo peso, difundidas pela Organização Mundial de Saúde (KRAMER 1987). revelam que $16 \%$ dos $\mathrm{RN}$ apresentaram peso inferior a $2500 \mathrm{~g}$. e, destes, $90 \%$ nasceram nos países em desenvolvimento. Cabe lembrar que, desses RN com baixo peso, a proporção de RN com RCIU é maior também nos países em desenvolvimento $(75 \%)$, atribuindo-se este fato à desnutrição materna, ao contrário do que acontece nos paises desenvolvidos, onde a desnutrição materna é responsável por apenas $33 \%$ do $\mathrm{RCIU}$.

Os métodos mais precisos (biometria fetal) para diagnóstico precoce de uma situação desfavorável do feto ainda não estão ao alcance da grande maioria da população. Na era da avançada tecnologia, é tentador poder se valer desses recursos para a prática diária, pois facilitam o trabalho; no entanto cabe lembrar que inclusive essas técnicas estão sujeitas a erros. Assim, os métodos convencionais de ultra-sonografia (USG) para determinação do peso ao nascer, podem chegar a ter até $15 \%$ de erro (LEE e col. 1997), enquanto o método da USG tridimensional chega até a $10 \%$ de erro.

Deste modo, métodos mais simples, como é o caso das medidas antropométricas da mãe, podem revelar-se técnicas que se adaptam melhor às 
necessidades do dia a dia dos serviços básicos de saúde. Estas medidas têm sido aceitas como boas preditoras do resultado da gravidez, melhores, por exemplo, do que as avaliações de consumo calórico (JOHNSON e col. 1994).

O peso, a estatura, o ganho de peso materno, o peso pré-gestacional, perímetro braquial, entre outras medidas antropometricas maternas, foram estudados como preditores do peso ao nascer (SIQUEIRA 1979; FRISANCHO 1977a; NAEYE 1979; TANAKA 1980; WINIKOFF 1981; LECHTIG 1988; BULL. WHO 1995; RICALDE 1988).

Contudo, persistem dificuldades para estabelecer o ponto de corte mais apropriado para as diferentes medidas, já que estas variam entre os paises desenvolvidos e em desenvolvimento (KRAMER 1987; BULL WHO 1995), e, desta maneira, a utilidade destes indicadores para diagnóstico de estado nutricional materno fica restrita às populaçōes abrangidas por tais estudos.

Assim, por exemplo, o ganho de peso gestacional (GPG) parece ser um indicador altamente sensivel, quando se aplica em mulheres que entraram na gravidez com um peso pré-gestacional (PPG) abaixo do percentil 10. Por isso, - GPG recomendado difere entre as mulheres com deficiência de peso prégravídico e as que apresentam peso "normal" e sobrepeso (JERE 1991). Mesmo assim, é dificil recomendar um padrão de ganho de peso gestacional, devido à grande variação que o mesmo apresenta, inclusive em mulheres saudáveis com resultado favorável da gestação.

Estas considerações são importantes quando se faz avaliação de GPG, 
pois não está em discussão o incremento de peso na gestante como uma das variáveis moderadoras do crescimento fetal; a única dificuldade ainda reside na medição do PPG, em função do qual se faz a avaliação de GPG, dado que essa informação é obtida por interrogatório ou estimada.

A dificuldade aumenta nos casos onde a assistência pré-natal à mulher gestante, acontece, em média, no segundo trimestre da gravidez (GUERI e col. 1982; RICALDE 1994), e então, a estimativa ou a informação do PPG estaria sujeita a erros, por depender da memória da informante.

Além disso, como já foi mencionado, os padrões recomendados de ganho de peso gestacional são diferentes para os países desenvolvidos e em desenvolvimento (PAHO 1991). Por outro lado, se assumir que a gestação é um evento ímpar, do ponto de vista fisiológico, então, por que ter padrões diferentes de ganho de peso na gravidez?

Esta indagação nos leva a pensar na existência de outros fatores que ainda não foram bem controlados pelas pesquisas, e que interferem na determinação do ponto de corte do indicador para predizer resultados não favoráveis da gestação, como é o caso do baixo peso ao nascer (BPN).

Resultados de algumas pesquisas (KHAN et col. 1996; RICALDE e col. 1996) revelam a ausência de associação entre ganho de peso da gestante e o BPN. Por outro lado, JOHNSON e col. (1996) constataram associação entre ganho de peso gestacional e peso do recém nascido, apesar de esta associação não ser muito elevada $(r=0,26)$; em estudo sobre a nutrição materna 
e resultados da gravidez (KRASOVEC e ANDERSON 1991) afirma-se que o efeito favorável do ganho de peso é mais importante nas gestantes desnutridas Então surgem outras indagações, tais como: o que se pretende efetivamente com a avaliação do ganho de peso da gestante? predizer resultado da gravidez, ou avaliar reservas nutricionais maternas?

Frente a esse quadro, que apresenta resultados contraditórios, recomenda-se muita cautela na utilização desse indicador (GPG), e, mais que isso, a necessidade de aprimoramento de estudos para responder a essas questões, que ainda são motivo de controvérsias.

Outro tema, que parece dividir as opiniões dos pesquisadores, é a utilização da estatura materna como indicador de resultado de gravidez. Enquanto alguns autores ainda referem-se a ela como um indicador de risco de baixo peso ao nascer (PRENTICE e col. 1987; KARDJATI e col. 1988; PAHO 1991), outros autores verificaram que não existe correlação entre o peso ao nascer e a estatura materna ( RUSH e SUSSER 1972; NISWANDER 1974; RICALDE e col. 1998). É importante ressaltar que as associações encontradas com o BPN referem-se a estaturas maternas muito baixas (NISWANDER e col. 1974; SIQUEIRA 1975; HUSAINI e col. 1986).

Assim, o uso da estatura materna como indicador de risco de BPN está restrito às mães com muito baixa estatura. Mesmo assim, não se pode esquecer que existem outros fatores que são moderadores e/ou "estimuladores" do crescimento fetal e que são mais determinantes do que a estatura da mulher, 
como é o caso do ganho de peso gestacional no terceiro trimestre (BERGNER e SUSSER, 1970), e o peso pre-gestacional que, como foi demonstrado, exerce uma influência importante, independentemente de outros fatores (SMITH, 1947; NAEYE, 1979; BULL WHO, 1995).

A esse respeito, há um consenso nas publicações tanto em países desenvolvidos como em desenvolvimento, acerca da forte associação entre o peso pre-gestacional e o peso ao nascer, como foi demonstrado por KRAMER (1987), na sua revisão sobre os determinantes do baixo peso ao nascer. O que ainda é discutível é como obter a medida do PPG de maneira mais confiável e precisa, para ser usada seja nas curvas de GPG, seja em combinação com outros indicadores, para predizer o peso ao nascer.

Diante disso fica, então, a pergunta: em que condições o PPG pode ser utilizado como instrumento de diagnóstico de gestantes com risco de ter recémnascido de baixo peso (RNBP)?. Esta pergunta ainda requer respostas consistentes.

Devido a essa dificuldade de estabelecer um critério padronizado para responder à questão, vários autores (SHAH 1982 e 1991; KRASOVEC 1989 e 1991; NEEL e ALVAREZ 1991; WHO 1995) têm se preocupado em investigar outros indicadores, que requerem apenas um contato com a gestante para estabelecer critérios de risco, que possam refletir os efeitos das privaçōes nutricionais anteriores ou atuais na gestação.

Como exemplo disso, o perimetro braquial (PB), que parece satisfazer 
essas condições (NEEL e ALVAREZ 1991), está sendo pesquisado amplamente, pois vem-se apresentando, como um indicador capaz de predizer peso ao nascer (MASSO e col. 1988; RICALDE e col. 1988) com alta sensibilidade e especificidade (LECHTIG 1988).

Assim, foi sugerido o PB como 0 indicador que poderia substituir a informação do PPG (SHAH 1991; OLUKOYA e GIWA 1991; RICALDE 1994). Fundamentos para tal colocação existem: por exemplo, HEDIGER e col. (1994) verificaram que há uma correlação estatisticamente significante entre a área de tecido adiposo do braço e o peso pré-gravídico. Ao mesmo tempo as variações, tanto na área muscular do braço, quanto na gordurosa, refletiram-se em variações no peso ao nascer. De fato, as mudanças do tecido adiposo ou muscular do braço vão se refletir em mudanças na medida do PB, outros estudos também mostraram uma forte relação entre o peso da mulher e $\circ$ perímetro braquial (TIBREWALA e SHAH 1978; SHAH 1982; HUFFMAN 1985; ANDERSON 1989; KRASOVEC 1989; RICALDE 1994), o que significaria que as mudanças que ocorrem no peso corporal vão se refletir em mudanças no PB.

No caso da gestação, em especial, estas relações são independentes da idade gestacional (LECHTIG 1988; RICALDE 1994), o que permite supor que o perímetro braquial poderia ser um bom indicador da condição pré-gravídica, mesmo medido durante a gravidez.

Por outro lado, estudos preliminares sobre as médias do PB observadas nas pesquisas realizadas em outros países, têm variado de $21,3 \mathrm{~cm}$. 
(ANDERSON 1989) até 26,0 (BRIEND 1980), o que reflete estados nutricionais diferentes. No primeiro estudo trata-se de mulheres Indianas, que em sua maioria, apresentaram situação nutricional desfavorável.

Já no estudo de BRIEND (1980) trata-se de uma população heterogênea, com perfil nutricional considerado de caracteristicas normais. No Brasil, os estudos indicam uma média de $27,0 \mathrm{~cm}$ para uma população de mulheres sadias (SIQUEIRA 1979; DESAI 1980). Devido a essa grande variabilidade do $\mathrm{PB}$, os pontos de corte, recomendados para identificar mulheres em risco de ter recém-nascido de baixo peso, são diversos para diferentes países.

Outra situação ainda controversa, e que não permite a padronização dos pontos de corte do perímetro braquial como indicador de risco de BPN, é o fato de que as pesquisas revelam diversas variações desse indicador durante a gravidez. Assim, por exemplo, enquanto alguns autores constataram um aumento da medida do PB durante o segundo e terceiro trimestres (BISSENDEN 1981; METCOFF 1986), outros (HULL 1983; JANSEN 1984; ANDERSON 1989; KRASOVEC 1989) verificaram o decréscimo do perímetro braquial, principalmente no terceiro trimestre da gravidez, e, ainda outras pesquisas encontraram uma relativa estabilidade do PB durante a gestação (SHAH 1991; RICALDE 1994).

Finalmente, em relação ao PB como preditor do PPG, foram obtidas estimativas diferentes de peso pre-gestacional para o mesmo ponto de corte do perímetro braquial em diferentes países, apesar de que os modelos preditivos 
utilizados foram considerados não viciados (WHO 1995), mesmo tendo tamanhos amostrais diferentes entre os estudos feitos em diferentes paises.

Essas controvérsias sugerem a necessidade de pesquisar mais sobre 0 PB, e responder a questões como:

Em que medida o perimetro braquial estaria explicando o mesmo que explica a relação peso/estatura/idade, em primeiro lugar, e peso/estatura/idade gestacional em segundo lugar?

É possível predizer o peso ao nascer através da medida do PB? Quais seriam os pontos de corte que identificariam uma gestante em risco de ter um recém-nascido de baixo peso?

Será que a medida do PB é aplicável a todas as gestantes, ou este somente seria útil em casos especificos, com situações nutricionais específicas?

Em que medida o PB poderia estar substituindo a informação do peso pre-gestacional?

E finalmente o que a medida do PB pode realmente indicar?

Para responder a estas e outras questões sobre o perímetro braquial da gestante, se propôs realizar o presente estudo. É importante assinalar que o interesse em pesquisar o PB, surgiu das seguintes constatações:

1) O PB tem uma confiabilidade igual ou maior de $0,97 \%$ (MARKS e col., 1989).

2) O erro inter-observadores está estimado em $3,8 \%$ ou menos, enquanto que, 
quando a medida é obtida pelo mesmo observador o erro cai para $2,2 \%$ (BISHOP E PITCHEY 1987).

3) Outros estudos (ZERFAS 1985; BULL WHO 1995) verificaram um erro de apenas $\pm 0,2 \mathrm{~cm}$, quando o pessoal é bem treinado.

Essas evidências revelam a vantagem desse indicador, além de outras que respondem a duas questões importantes:

Primeiro, que o PB é um indicador de estado nutricional materno, devido ao fato de que, na sua composição (osso, músculos, nervos, vasos sangüíneos, tecido adiposo e pele), estão representadas as reservas calórico-protéicas do indivíduo.

Segundo, porque o PB satisfaz as condições de ser um indicador com boa reprodutibilidade, de elevada sensibilidade e especificidade, requerendo tecnologia simples e de baixo custo, além de treinamento simples e fácil aplicação nos serviços de saúde.

No Brasil, são poucos os trabalhos que tem estudado o perímetro braquial como indicador de estado nutricional das gestantes e como indicador de risco de ter um recém-nascido de baixo peso ou peso inadequado. A Pastoral da Criança vem desenvolvendo o trabalho de diagnostico de gestantes desnutridas utilizando a fita braquial para a medição do perimetro braquial. (PASTORAL DA CRIANÇA 1997). 


\section{OBJETIVOS}




\section{OBJETIVOS}

\subsection{Objetivo Geral:}

Analisar o uso do perímetro braquial como indicador do estado nutricional materno e como preditor do peso ao nascer.

\subsection{Objetivos Específicos:}

- Verificar a relação do perímetro braquial da gestante com outros indicadores antropometricos maternos.

- Estabelecer o ponto de corte do PB, com adequada sensibilidade, especificidade e valor preditivo positivo, capaz de predizer o peso do recémnascido.

-. Propor um instrumento que use o perímetro braquial, associado ou não a outras variáveis antropométricas maternas, capaz de medir o risco da gestante ter um recém nascido de peso inadequado. 
PROCEDIMENTO METODOLÓGICO 


\section{PROCEDIMENTO METODOLÓGICO}

\subsection{DESENHO DO ESTUDO}

Foi realizado um estudo de coorte em mulheres gestantes, e seus respectivos recém-nascidos, inscritas nos serviços de pré-natal do Hospital Universitário da Universidade de São Paulo e do Centro de Saúde Escola "Samuel B. Pessoa" da região do Butantã, na cidade de São Paulo.

\subsection{POPULAÇÃO}

- Gestantes nos três trimestres da gestação, matriculadas no serviço de prénatal das unidades seleccionadas para o estudo, e que realizaram o parto no Hospital Universitário, por ser o hospital de referencia do pré-natal de ambas unidades. O período de estudo teve inicio em maio de 1997 e término em abril de 1999.

- Recém-nascidos das respectivas gestantes.

\subsection{PROCEDIMENTOS PARA AMOSTRAGEM}

Considerando uma frequência de $35,4 \%$ de recém-nascidos com peso inferior a 3,000 gramas (FUNDAÇÃO SEADE, 1994) para o municipio de São Paulo, foi constituida uma amostra de conveniência de mulheres gestantes, e seus respectivos recém-nascidos. A estimativa da amostra, com um nível de $95 \%$ de confiança, para uma sensibilidade esperada de $50 \%$ com uma precisão de $9 \%$ $(d=0,09)$, e para uma especificidade de $70 \%$ com uma precisão de $6 \%(d=0,06)$, 
seria em torno de 119 casos de recém-nascidos com peso inferior a 3,000 gramas, em uma corte de $\mathbf{3 5 0}$ gestantes. Para se chegar a esta amostra final foram colectados os dados de $\mathbf{4 1 4}$ gestantes, havendo perdas ocasionadas por: mudança de local do parto, fato conhecido somente após a verificação da data provável de parto; mudança de endereço das mulheres, e exclusão de questionários na hora da avaliação e análise da consistência dos dados.

\subsection{DELINEAMENTO DA PESQUISA}

A investigação foi feita em etapas:

A primeira etapa foi de selecção das participantes no estudo (amostra). As gestantes foram entrevistadas uma única vez, nessa ocasião foram realizadas as medições antropométricas e a verificação da bacteriuria assintomática.

$\mathrm{Na}$ segunda etapa foi verificado, através dos prontuários, se a gestante incluída no estudo foi diagnosticada com patologias ou afecçőes que pudessem alterar severamente o crescimento fetal (critérios de exclusão).

A terceira etapa foi de acompanhamento das participantes até a verificação do acontecimento do parto, para realizar as medições antropométricas do recémnascido.

\subsection{CRITÉRIOS PARA SELEÇÃO DA POPULAÇÃO}

Critérios de Inclusão:

. Idade materna entre 20 e 40 anos.

. Em qualquer trimestre da gravidez.

. Todos os recém-nascidos das gestantes que entrarem no estudo. 


\section{Critérios de Exclusão:}

. Mulheres que registrem patologia diagnosticada como infecçöes congénitas, anomalias congénitas do útero e placenta, cromossomopatias, gravidez múltipla, infarto placentário, DPP crónico, patologias placentárias, nefropatia crónica, colagenoses, cardiopatias, diabetes avançado e doença hipertensiva especifica da gravidez não tratada, infecção do trato urinário não tratada.

. Recém-nascidos macrossômicos e com malformaçōes congénitas.

. Parto prematuro (< 37 semanas de gestação).

\subsection{TÉCNICAS UTILIZADAS NA COLETA DE DADOS}

O instrumento para colecta de dados foi um questionário (ver anexo A5), incluindo dados gerais de identificaçăo, dados sobre a situação sócioeconômica, sobre o pré-natal; dados antropométricos, idade materna, idade gestacional da mãe e do recém-nascido. Também foram colectadas informaçōes acerca de hábitos relacionados com álcool, cigarro e/ou droga que podem ter ocorrido durante a gestação. Foi verificada a informação sobre bacteriuria assintomática e a condição de tratada ou não. As mediçōes dos indicadores antropométricos foram feitas de acordo com os padröes recomendados pela Organização Mundial de Saúde (WHO 1995).

\subsection{PROCEDIMENTOS NA COLETA DE DADOS}

\section{Na gestante:}

. As gestantes foram captadas em função dos critérios estabelecidos, 
nos serviços escolhidos e no horário da consulta pré-natal, seguindo a técnica de sorteio aleatório simples.

. O preenchimento do "formulário de dados" foi realizado na entrevista pessoal com cada mulher, no mesmo dia do sorteio.

. As medições antropométricas foram realizadas por uma única observadora, quem seguiu as normas recomendadas pela Organização Mundial da Saúde (WHO 1995).

. O peso pré-gestacional foi obtido por interrogatório.

- A idade gestacional foi calculada a partir da data de última menstruação, e a idade gestacional pela Ultra-sonografia foi obtida do prontuário da gestante.

\section{No recém-nascido:}

. Os recém nascidos foram captados no berçário do Hospital Universitário e foram avaliados clinica e antropométricamente, nas primeiras 60 horas de vida.

. Foram realizadas as medidas de peso, perímetro cefálico, perímetro torácico, perímetro abdominal, segundo padrões estabelecidos, tais medições foram realizadas por uma única observadora, previamente treinada.
. A idade gestacional foi estimada pelo método de Dubowitz, assim como foram avaliadas as condições do nascimento através da escala de APGAR, este último dado foi obtido do prontuário do recém-nascido. 


\subsection{APURAÇÃO E ANÁLISE DOS DADOS}

Todos os dados foram armazenados num banco de dados do programa EPIINFO versão 5 (DEAN et al. 1990). Para a estatística simples como as frequências, médias e desvios padrões das variáveis estudadas foi utilizado o mesmo programa.

Testes bivariados (Pearson correlation, odds ratio) foram realizados para verificar uma primeira relação entre a antropometria materna e o peso do recémnascido.

Análises de regressão linear simples foi utilizada para verificar a relação entre as variáveis antropometricas maternas e o peso do recém-nascido. Os testes estatísticos citados anteriormente foram realizados para verificar a relação entre o perímetro braquial e o peso pré-gestacional.

Testes de sensibilidade, especificidade e valor preditivo positivo do perímetro braquial, foram realizados para estabelecer o melhor ponto de corte do PB capaz de predizer baixo peso ao nascer e peso inadequado $(<3000)$.

Foi elaborado um índice utilizando a estatura e perímetro braquial maternos, para determinar em que valores a gestante apresenta o risco de ter recém nascido de peso inadequado. Foi construída uma curva de referencia para tais valores, considerando os diferentes percentis do perímetro braquial para as diferentes idades da gestante. Foram considerados três níveis de risco (leve, moderado e grave), baseados no índice, para ter um recém-nascido de peso inadequado. A curva foi elaborada utilizando o programa "Curve Expert". 
As diferenças entre as variáveis estudadas foram consideradas estatisticamente significativas quando $P \leq 0,05$. 
RESULTADOS E DISCUSSÃO 


\section{RESULTADOS E DISCUSSÃO}

\subsection{Características Gerais da População Estudada}

No presente estudo, foram analisados os dados antropometricos de 350 gestantes, trata-se de uma população com uma media de 10 anos $( \pm 4)$ de escolaridade. Com hábitos nocivos pouco frequentes $(89,1 \%$ não fumantes e $100 \%$ não alcoólatras); com uma renda familiar em media de $10,7( \pm 8,0)$ salários mínimos (R\$1288, 81 reais). Apenas duas gestantes tinham renda de 1 salário mínimo ( $R \$ 120,00$ reais) e $81,4 \%$ tinham mais de cinco salários mínimos.

A média das gestações da população estudada foi de $2( \pm 1,5)$ gestações, uma proporção menor das gestantes tinha mais de três gestações $(15,2 \%)$ das quais apenas $0,8 \%$ tiveram nove gestações incluindo a actual, e $42,8 \%$ eram primigestas. Do total de gestantes $17,2 \%$ tinham historia de 1 aborto e $1,2 \%$ tinham 4 ou mais abortos. Do total das gestantes $14,5 \%$ apresentaram bacteriuria assintomatica durante a gestação das quais quase a totalidade receberam tratamento com excepção de uma gestante.

O peso pre-gestacional informado esteve em media de $58,7 \mathrm{~kg}( \pm 10,3)$.

O peso das gestantes ao entrar no estudo esteve em media de $61,1 \mathrm{~kg}( \pm 9,1$ kg.) no primeiro trimestre, com uma idade gestacional em média de $9,0( \pm 3,0)$ 
semanas. No segundo trimestre o peso médio ao entrar no estudo esteve em $61,7 \mathrm{~kg}( \pm 9,1 \mathrm{~kg}$.) com idade gestacional media de $19,0( \pm 4,1)$ semanas. As gestantes que entraram no estudo no terceiro trimestre tiveram um peso médio de $70,3 \mathrm{~kg}$ ( $\pm 12,3 \mathrm{~kg}$.) e uma idade gestacional media de $32,0( \pm 4,5)$ semanas.

A altura das gestantes era em media de $158,6 \mathrm{~cm}( \pm 6,67 \mathrm{~cm}$.$) A media$ do perímetro braquial esteve em $26,4 \mathrm{~cm}$. $( \pm 3,2)$. 0 mesmo foi de $26,4 \mathrm{~cm}$ ( \pm $2,3)$ em media no primeiro trimestre, $26,2( \pm 3,3)$ no segundo e $26,7( \pm 3,3)$ no terceiro trimestre.

$O$ indice de massa corporal (IMC), foi calculado utilizando a formula de Quetelet (WHO 1995), este indice esteve em média em 24,1 ( $\pm 3,7$ ) no primeiro trimestre; $24,9( \pm 4,2)$ no segundo trimestre e $27,6( \pm 4,2)$ no terceiro trimestre.

O perímetro braquial das gestantes, que entraram no estudo no primeiro trimestre, foi em média de $26,4 \mathrm{~cm}$ ( $\pm 2,3$ ); para as gestantes do segundo trimestre o PB ficou em media de $26,2 \mathrm{~cm}( \pm 3,3)$ e no terceiro trimestre as gestantes apresentaram um PB médio de $26,7 \mathrm{~cm}( \pm 3,3)$. Quando foi analisada a media do perímetro braquial de todas as gestantes, independente da idade gestacional, o PB ficou em $26,4 \mathrm{~cm} \quad( \pm 3,3)$.

As condições de nascimento dos filhos das gestantes foram em geral boas. O APGAR do primeiro minuto ao nascer esteve em media de $8( \pm 0,8)$ 
pontos. A idade gestacional pelo método de CAPURRO foi em media de 38,6 ( \pm 1,2) semanas, e pelo método de DUBOWITZ a idade gestacional dos mesmos foi de 38,2 semanas $( \pm 1,2)$. O peso do recém-nascido esteve em media de $3199,7 \mathrm{~g}( \pm 487,3)$. O peso do filho anterior foi em media de 3194 gramas $( \pm$ $616,0)$. Para ilustração dos dados apresentam-se as tabelas 1, 1.1,1.2 e 2 .

TABELA 1. DISTRIBUIÇÃO DAS GESTANTES SEGUNDO IDADE GESTACIONAL POR TRIMESTRES, MEDIA DE DESVIO PADRAO DA IDADE GESTACIONAL SEGUNDO A DATA DA ULTIMA MENSTRUAÇÃO (DUM) $(\mathrm{N}=350)$

\begin{tabular}{ccccc}
\hline $\begin{array}{c}\text { TRIMESTRE } \\
\text { DA } \\
\text { GESTACÃO }\end{array}$ & $\begin{array}{c}\text { SEMANAS } \\
\text { DA } \\
\text { GESTAÇÃO }\end{array}$ & $\begin{array}{c}\text { NUMERO DE } \\
\text { GESTANTES }\end{array}$ & $\begin{array}{c}\text { IDADE } \\
\text { GESTACIONAL } \\
\text { MEDIA }\end{array}$ & $\begin{array}{c}\mathbf{N} \\
\text { TOTAL }\end{array}$ \\
\hline I. Trimestre & $5-10$ & 44 & $9( \pm 3,0)$ & 64 \\
& $11-13$ & 20 & & \\
II. Trimestre & $14-20$ & 82 & $19( \pm 4,1)$ & 142 \\
& $21-26$ & 60 & & \\
III. Trimestre & $27-32$ & 85 & $32( \pm 4,5)$ & 144 \\
& $33-40$ & 59 & & \\
\hline
\end{tabular}


TABELA 1.1 MÉDIA, DESVIO PADRÃO E MEDIANA DAS VARIAVEIS ESTUDADAS NAS GESTANTES ( $\mathrm{N}=350)$.

\begin{tabular}{cccc}
\hline VARIÁVEL & MEDIA & DP & MEDIANA \\
\hline IDADE & 29 & 7 & 28 \\
ANOS DE INSTRUÇÃO & 10,4 & 4,1 & 11 \\
RENDA FAMILIAR (reais) & 1288,8 & 967,1 & 1000 \\
NUMERO DE GESTAÇOES & 2,2 & 1,5 & 2 \\
NUMERO DE PARTOS & 0,8 & 1,1 & 1 \\
NUMERO DE ABORTOS & 0,3 & 0,8 & 0 \\
ALTURA (cm.) & 158,6 & 6,6 & 158 \\
PERIMETRO BRAQUIAL(cm) & & & \\
I TRIMESTRE & 26,4 & 2,3 & 26,4 \\
II TRIMESTRE & 26,2 & 3,3 & 26,0 \\
III TRIMESTRE & 26,7 & 3,3 & 26,1 \\
PESO PRE GESTACIONAL & 58,7 & 10,3 & 57,0 \\
INFORMADO (kg) & & & \\
PESO AO ENTRAR NO & & & \\
ESTUDO (kg): & & & \\
I TRIMESTRE & 61,1 & 9,1 & 59,6 \\
II TRIMESTRE & 61,7 & 11,0 & 61,0 \\
III TRIMESTRE & 70,3 & 12,3 & 68,5 \\
INDICE DE MASSA & & & \\
CORPORAL (IMC): & & 3,7 & 24,0 \\
I TRIMESTRE & 24,1 & 4,2 & \\
II TRIMESTRE & 24,9 & 27,6 & \\
III TRIMESTRE & & & \\
\hline
\end{tabular}


TABELA 1.2. DISTRIBUIÇÃO DAS GESTANTES SEGUNDO

SALARIO MINIMO (R\$ 120,00) ( $\mathrm{N}=350$ )

\begin{tabular}{ccc}
\hline SALARIOS MINIMOS & N & $\%$ \\
\hline 1 & 2 & 0,5 \\
2 & 4 & 1,1 \\
3 & 9 & 2,6 \\
4 & 10 & 3,0 \\
5 & 40 & 11,4 \\
+5 & 285 & 81,4 \\
\hline TOTAL & 350 & 100,0 \\
\hline
\end{tabular}

TABELA 2. MÉDIA, DESVIO PADRÃO E MEDIANA DAS VARIAVEIS ESTUDADAS NOS RECÉM-NASCIDOS ( $\mathrm{N}=350)$.

\begin{tabular}{cccc}
\hline VARIÁVEL & MEDIA & DP & MEDIANA \\
PESO AO NASCER $(\mathrm{kg})$ & 3199,7 & 487,2 & 3175,0 \\
$\begin{array}{c}\text { IDADE GESTACIONAL - } \\
\text { METODO CAPURRO }\end{array}$ & 38.6 & 1,2 & 39,0 \\
$\begin{array}{c}\text { IDADE GESTACIONAL - } \\
\text { METODO DUBOWITZ } \\
\text { BAIXO PESO AO NASCER } \\
\quad(n=20)\end{array}$ & 38,2 & 1,1 & 38,0 \\
$\begin{array}{c}\text { PESO INADEQUADO AO } \\
\text { NASCER (n=122) }\end{array}$ & 2376,3 & 151,7 & 2415,0 \\
$\begin{array}{c}\text { PESO DO RN ANTERIOR } \\
\text { INFORMADO (Ng) } 8\end{array}$ & 3196,0 & 616,8 & 3250,0 \\
$\begin{array}{c}\text { APGAR AO PRIMEIRO } \\
\text { MINUTO }\end{array}$ & 8,3 & 0,8 & 8,0 \\
\hline
\end{tabular}


Tais resultados sugerem afirmar que foram recém nascidos de termo, de mães saudáveis, sem os riscos evidentes para se ter um recém - nascido em condições desfavoráveis, como seria o caso do baixo peso ao nascer. No entanto, foi observado que $5,7 \%$ dos recém-nascidos tiveram peso inferior a 2500 gramas, e 40,6\% tiveram peso inadequado ao nascer ( $<3000 \mathrm{~g})$.

\subsection{Peso Pré-Gestacional e Ganho de Peso}

No presente estudo a medida do peso pre-gestacional (PPG) foi obtida através do interrogatório da própria gestante. O PPG, informado, esteve em média de $59,2 \mathrm{~kg}$. no primeiro trimestre. O peso ao entrar no estudo para as mesmas gestantes foi de $61,1 \mathrm{~kg}$. Verifica-se uma diferença de peso entre estas médias de $1,9 \mathrm{~kg}$. Se assumirmos que no primeiro trimestre da gestação o peso ganho está aproximadamente entre 1-2 kg. (GUERI e col. 1982), as gestantes estudadas tiveram um ganho de peso esperado no primeiro trimestre ( ver tabela $\mathrm{N}^{\circ} 3$ ).

Por outro lado, se levarmos em consideração que o incremento do peso para uma gravidez de termo deveria ser $20 \%$ do seu PPG, isto significaria que estas gestantes deveriam ganhar durante toda a gravidez $11,84 \mathrm{~kg}$., no caso das gestantes que informaram no primeiro trimestre, e $11,42 \mathrm{~kg}$ se partimos dos 
dados das gestantes que informaram no segundo trimestre e finalmente 12,02 $\mathrm{kg}$ se considerarmos o PPG informado no terceiro trimestre.

TABELA 3. MEDIA, E DESVIO PADRÃO DO PESO PRE-GESTACIONAL INFORMADO, PESO NA CONSULTA AO ENTRAR NO ESTUDO E IDADE GESTACIONAL POR TRIMESTRES, ( $N=350)$

\begin{tabular}{ccccc}
\hline $\begin{array}{c}\text { TRIMESTRE } \\
\text { DA } \\
\text { GESTACAO }\end{array}$ & N & $\begin{array}{c}\text { PESO PRE } \\
\text { GESTACIONAL } \\
\text { INFORMADO }\end{array}$ & $\begin{array}{c}\text { PESO NA } \\
\text { CONSULTA }\end{array}$ & $\begin{array}{c}\text { IDADE } \\
\text { GESTACIONAL } \\
\text { (DUM) }\end{array}$ \\
\hline I. Trimestre & 64 & $59,2( \pm 8,4)$ & $61,1( \pm 9,1)$ & $9,0( \pm 3,0)$ \\
II. Trimestre & 142 & $57,1( \pm 10,2)$ & $61,7( \pm 11,0)$ & $19,0( \pm 4,1)$ \\
III. Trimestre & 144 & $60,1( \pm 10,9)$ & $70,3( \pm 12,3)$ & $32,0( \pm 4,5)$ \\
\hline
\end{tabular}

No caso das gestantes estudadas no terceiro trimestre verifica-se um ganho de peso de $10,2 \mathrm{~kg}$, sendo assim há uma diferença de $2,00 \mathrm{~kg}$ do peso esperado para uma gravidez de termo. Se levarmos em consideração que o ganho de peso médio nos paises em desenvolvimento está entre 5 e $9 \mathrm{~kg}$. (KRASOVEC e ANDERSON, 1991), estas mulheres estariam com um ganho de peso adequado. Os resultados apresentam-se na tabela 3.

Estes achados conduziriam a diferentes conclusōes, e portanto permitiriam inferir que: o peso pré-gestacional informado e/ou estimado está sujeito à imprecisão, o que torna discutivel seu uso como ponto de partida nas 
curvas de avaliação de ganho de peso da gestante, e por tanto como preditor de resultados não favoráveis da gestação, principalmente no que diz respeito ao baixo peso ao nascer. No caso destas gestantes provavelmente houveram outros fatores não nutricionais que interferiram no ganho de peso esperado, que se baseia no PPG informado.

As informações obtidas e as estimativas baseadas no PPG não permitem observar uma homogeneidade de ganho de peso, este fenómeno talvez possa explicar o baixo valor predito das curvas de diagnóstico do estado nutricional materno baseadas no peso pre-gestacional. LAEL (1994), aplicando a curva de ROSSO (1985), verificou discrepâncias no diagnóstico de estado nutricional de gestantes ao comparar essa técnica com outras.

\section{3 Perímetro Braquial}

Dadas as vantagens práticas e a habilidade de predizer resultados da gravidez o perímetro braquial (PB) foi recomendado por vários autores (SHAH 1982; LECHTIG 1988; ANDERSON 1989; KRASOVEC 1989).

As pesquisas realizadas sobre o perímetro braquial são unânimes em recomendar este indicador para identificar gestantes em risco de ter um recémnascido de baixo peso, no entanto existem diferenças significativas entre os 
pontos de corte estabelecidos por alguns autores, o que pode estar reflectindo a realidade local onde forma realizados ditos estudos.

Passou-se então a verificar o que acontecia com esta população de gestantes, constata-se que, apenas 20 dos recém-nascidos apresentavam pesos inferiores a $2500 \mathrm{~g}$, ponto de corte recomendado para considerar um recém nascido de baixo peso (WHO 1995), o que representa $5.7 \%$ da população estudada.

Então, foi constatado nesta população uma prevalência muito baixa de baixo peso ao nascer $(\leq 2500 \mathrm{~g})$, o que estaria indicando que estas mulheres não apresentam as características comuns à população brasileira de um modo geral, onde tal prevalência esta em torno de $9,2 \%$ (UNICEF, 1998). No entanto deve-se lembrar que nesta população foram excluídos todos os recém-nascidos (RN) pré-termo, os quais constituem uma parcela importante dos RN de baixo peso.

Numa primeira análise, sobre a sensibilidade e especificidade do PB como indicador de baixo peso do recém-nascido (RN), escolheu-se como ponto de corte um PB menor ou igual a $22,1 \mathrm{~cm}$, valor médio do primeiro quintil (Tabela 5), esta divisão em quintis se fez, para poder ter um numero maior de casos sendo examinados, cada quintil representa $20 \%$ da população estudada. Verificou-se que o PB $\leq 22,1 \mathrm{~cm}$ apresenta uma sensibilidade baixa (10\%) e uma especificidade alta (91\%) para predizer baixo peso do recém nascido, e um 
valor preditivo igual a $6 \%$. Os dados que se utilizaram para o calculo destes indicadores apresentam-se na Tabela 4.

TABELA 4. SENSIBILIDADE E ESPECIFICIDADE DO PERIMETRO BRAQUIAL $\leq 22,1$ PARA PREDIZER BAIXO PESO AO NASCER $(\leq 2500)$

\begin{tabular}{cccc}
\hline PB & BAIXO PESO & PESO NORMAL & TOTAL \\
\hline$\leq 22,1$ & $\mathrm{~cm})$ & $\mathbf{N}$ & $\mathbf{N}$ \\
$>22,1$ & 2 & 29 & 31 \\
\hline TOTAL & 18 & 301 & 319 \\
\hline
\end{tabular}

SENSIBILIDADE $=0,10(10 \%)$, ESPECIFICIDADE $=0,91(91 \%)$, VPP= $0,06(6 \%)$. Odds ratio $=1,15 \quad 1 C=0,00-5,63$

Este achado estaria contradizendo resultados obtidos e propostos em pesquisas anteriores, como seria o caso da Guatemala, onde um perímetro braquial $<22.5 \mathrm{~cm}$ é proposto como indicador de baixo peso ao nascer (WHO 1995).

No caso do Brasil é proposto um PB $<23.5 \mathrm{~cm}$, ao testar este ponto de corte, verifica-se que, nesta população, o perímetro braquial $<23.5 \mathrm{~cm}$, 
apresenta uma melhoria na sensibilidade (45\%) e continua com boa especificidade (83\%), e o valor preditivo positivo aumenta para $14 \%$; com um $p=0,0042$. Os dados são mostrados na tabela 4.1

TABELA 4.1 SENSIBILIDADE E ESPECIFICIDADE DO PERIMETRO BRAQUIAL $\leq 23.5$ PARA PREDIZER BAIXO PESO AO NASCER $(\leq 2500)$

\begin{tabular}{rccc}
\hline PB & BAIXO PESO & PESO NORMAL & TOTAL \\
\hline $\mathrm{cm})$ & $\mathrm{N}$ & $\mathrm{N}$ & $\mathrm{N}$ \\
\hline 23.5 & 9 & 55 & 64 \\
$>23.5$ & 11 & 275 & 286 \\
\hline TOTAL & 20 & 330 & 350 \\
\hline
\end{tabular}

Sensibilidade $=0.45(45 \%)$, Especificidade $=0.83(83 \%)$, VPP $=0.14(14 \%)$. Odds ratio $=4,09 \quad R R=3,66(1,58-8,45) \quad p=0,0042$

Devido a baixa prevalência de baixo peso encontrada nesta pesquisa $(5,7 \%)$, tornou-se necessário estudar quais seriam os pesos dos recémnascidos correspondentes as medidas do PB maternos, quando estes são classificados em quintis.

Constatou-se que, as medidas do perimetro braquial maternos baixos não necessariamente correspondiam a medidas baixas de pesos dos recémnascidos; assim por exemplo, a média do peso dos recém-nascidos, das mães classificadas no primeiro quintil (o menor) do PB, estava em torno de $2,869 \mathrm{~g}$; 
ou seja acima do peso considerado baixo ( $\leq$ a $2500 \mathrm{~g})$. Estes resultados são apresentados na tabela 5 .

No entanto, $28,37 \%(\mathrm{~N}=99)$ dos recém-nascidos tiveram pesos inferiores a média do peso do primeiro quintil $(\leq 2869)$. Ao mesmo tempo $39,0 \%$ (136) dos RN apresentaram peso inadequado $(<3000 \mathrm{~g})$ ao nascer Levando em consideração estes achados, e as recomendações da Organização Mundial de Saúde (WHO 1995), de que não existe um valor limite melhor a "priori" para estabelecer pontos de corte, passou-se a verificar a capacidade do perímetro braquial, em diversos pontos de corte, para predizer peso inadequado ao nascer (PIAN), considerado este um peso igual ou inferior a 3000 gramas.

Ao realizar novos testes de sensibilidade e especificidade para o PB $<22,1 \mathrm{~cm}$, levando em consideração o novo ponto de corte do peso do recémnascido ( $\leq 3000$ ), verificou-se uma melhora na sensibilidade (de 10 para $17 \%$ ) e na especificidade (de 91 para $96 \%$ ) e principalmente no valor preditivo positivo que ficou em $74 \%$ (ver tabela 6 ), para predizer peso inadequado ao nascer ( $\leq$ $3000)$. 
TABELA 5. MEDIA, DESVIO PADRÃO E MEDIANA DO PERIMETRO BRAQUIAL DAS GESTANTES, POR QUINTILES, MEDIA, DESVIO PADRÃO, MEDIANA DO PESO DO RECÉM-NASCIDO CORRESPONDENTE ( $\mathbf{N}=350)$

\begin{tabular}{lccccc}
\hline $\begin{array}{c}\text { QUINTIL } \\
\text { DO PB }\end{array}$ & $\begin{array}{c}\text { PB MEDIA E DP } \\
(\mathrm{cm} .)\end{array}$ & $\begin{array}{c}\text { MEDIANA } \\
\text { DO PB }\end{array}$ & $\begin{array}{c}\text { PESO DO RN } \\
\text { MEDIA E DP }(\mathrm{g} .)\end{array}$ & $\begin{array}{c}\text { MEDIANA } \\
\text { PESO RN }\end{array}$ & $\begin{array}{c}\mathrm{N} \\
350\end{array}$ \\
\hline $1^{\circ}$ & $22,1( \pm 1,2)$ & 22,5 & $2869,0( \pm 428,8)$ & 2800,0 & 70 \\
$\begin{array}{l}\text { Quintil } \\
2^{\circ}\end{array}$ & $24,6( \pm 0,4)$ & 24,6 & $3101,8( \pm 430,0)$ & 3105,0 & 70 \\
$\begin{array}{l}\text { Quintil } \\
3^{\circ}\end{array}$ & $26,1( \pm 0,4)$ & 26,0 & $3214,3( \pm 391,2)$ & 3250,0 & 70 \\
$\begin{array}{l}\text { Quintil } \\
4^{\circ}\end{array}$ & $27,7( \pm 0,6)$ & 28,0 & $3326,1( \pm 457,0)$ & 3350,0 & 70 \\
$\begin{array}{l}\text { Quintil } \\
5^{\circ} \\
\text { Quintil }\end{array}$ & $30,8( \pm 2,1)$ & 30,0 & $3440,4( \pm 510,5)$ & 3400,0 & 70 \\
\hline
\end{tabular}

Quando o ponto de corte do PB é definido em diferentes valores, até chegar ao valor máximo de $30 \mathrm{~cm}$, as diferentes variações da sensibilidade e especificidade do perimetro braquial materno chegam a determinar como melhor ponto de corte um PB entre 24,4 e $24,5 \mathrm{~cm}$.

Ambos pontos de corte apresentam o melhor valor preditivo positivo ( $71 \%$ ), com boa sensibilidade ( $48 \%$ ) e elevada especificidade ( $88 \%$ e $87 \%$ para - PB de 24,4 e 24,5 respectivamente) para predizer peso inadequado ao nascer. Para efeitos de aplicação prática, poderse-ia dizer que o melhor ponto de corte define-se como sendo um perímetro braquial menor ou igual a $24,5 \mathrm{~cm}$. 
Por outro lado, o ponto de encontro onde os valores da sensibilidade e especificidade do perímetro braquial são semelhantes, para predizer peso inadequado ao nascer, ficou no valor de $26,1 \mathrm{~cm}$. Para este ponto de corte o valor preditivo positivo (VPP) é de 53\%, a sensibilidade de $70 \%$ e a especificidade de $61 \%$ (ver tabela $6 a$ e 6 b e gráfico 1).

Com o objetivo de verificar se o PB da gestante associado a outras variáveis, poderia explicar melhor o risco de ter um RN com peso inadequado ao nascer, verificou-se, em primeiro lugar se havia alguma relação direta entre peso do recém nascido e o perímetro braquial da gestante através do teste de regressão linear simples.

Verificou-se que, a variação do perímetro braquial explica em $16 \%\left(r^{2}=\right.$ 0.16) a variação do peso do recém-nascido ( ver tabela 7); e a intensidade da associação entre estas duas variáveis esta em torno de $40 \%(r=0,40 \%)$, esta associação não é maior, provavelmente devido a que existem outros fatores não nutricionais que interferem no peso do RN. 
TABELA 6a. SENSIBILIDADE, ESPECIFICIDADE E VPP DO PERIMETRO BRAQUIAL MATERNO EM DIFERENTES PONTOS DE CORTE PARA PREDIZER PESO INADEQUADO AO NASCER $(\leq 3000)$

\begin{tabular}{|c|c|c|c|}
\hline $\begin{array}{c}\text { PONTO DE } \\
\text { CORTE DO PB }\end{array}$ & $\begin{array}{c}\text { SENSIBIIDADE } \\
(\%)\end{array}$ & $\begin{array}{c}\text { ESPECIFICIDADE } \\
(\%)\end{array}$ & VPP (\%) \\
\hline 22,1 & 0,17 & 0,96 & 0,74 \\
\hline 22,2 & 0,17 & 0,96 & 0,74 \\
\hline 22,3 & 0,17 & 0,96 & 0,74 \\
\hline 22,4 & 0,17 & 0,96 & 0,75 \\
\hline 22,5 & 0,17 & 0,96 & 0,75 \\
\hline 22,6 & 0,19 & 0,94 & 0,69 \\
\hline 22,7 & 0,19 & 0,94 & 0,69 \\
\hline 22,8 & 0,21 & 0,94 & 0,70 \\
\hline 22,9 & 0,21 & 0,94 & 0,70 \\
\hline 23,0 & 0,21 & 0,94 & 0,70 \\
\hline 23,1 & 0,28 & 0,93 & 0,72 \\
\hline 23,2 & 0,28 & 0,93 & 0,72 \\
\hline 23,3 & 0,28 & 0,93 & 0,72 \\
\hline 23,4 & 0,29 & 0,93 & 0,71 \\
\hline 23,5 & 0,31 & 0,93 & 0,72 \\
\hline 23,6 & 0,35 & 0,93 & 0,75 \\
\hline 23,7 & 0,37 & 0,93 & 0,76 \\
\hline 23,8 & 0,37 & 0,93 & 0,76 \\
\hline 23,9 & 0,38 & 0,93 & 0,76 \\
\hline 24,0 & 0,38 & 0,93 & 0,76 \\
\hline 24,1 & 0,44 & 0,88 & 0,70 \\
\hline 24,2 & 0,44 & 0,88 & 0,70 \\
\hline 24,3 & 0,44 & 0,88 & 0,70 \\
\hline 2,4 & 0,18 & 0,00 & 0,71 \\
\hline 24,5 & 0.0 & 0,07 & 0,74 \\
\hline 24,6 & 0,52 & 0,86 & 0,70 \\
\hline 24,7 & 0,52 & 0,86 & 0,70 \\
\hline 24,8 & 0,52 & 0,85 & 0,68 \\
\hline 24,9 & 0,52 & 0,85 & 0,68 \\
\hline 25,0 & 0,52 & 0,85 & 0,68 \\
\hline 25,1 & 0,58 & 0,74 & 0,59 \\
\hline 25,2 & 0,58 & 0,73 & 0,58 \\
\hline 25,3 & 0,58 & 0,73 & 0,58 \\
\hline 25,4 & 0,60 & 0,73 & 0,59 \\
\hline 25,5 & 0,62 & 0,73 & 0,60 \\
\hline 25,6 & 0,62 & 0,72 & 0,57 \\
\hline 25,7 & 0,63 & 0.72 & 0,58 \\
\hline 25,8 & 0,63 & 0,72 & 0,58 \\
\hline 25,9 & 0,63 & 0,72 & 0,58 \\
\hline 26,0 & 0,63 & 0,71 & 0,58 \\
\hline
\end{tabular}


TABELA 6b SENSIBILIDADE, ESPECIFICIDADE E VPP DO PERIMETRO BRAQUIAL MATERNO EM DIFERENTES PONTOS DE CORTE PARA PREDIZER PESO INADEQUADO AO NASCER $(\leq 3000)$

PONTO DE SENSIBIIDADE ESPECIFICIDADE VPP (*)

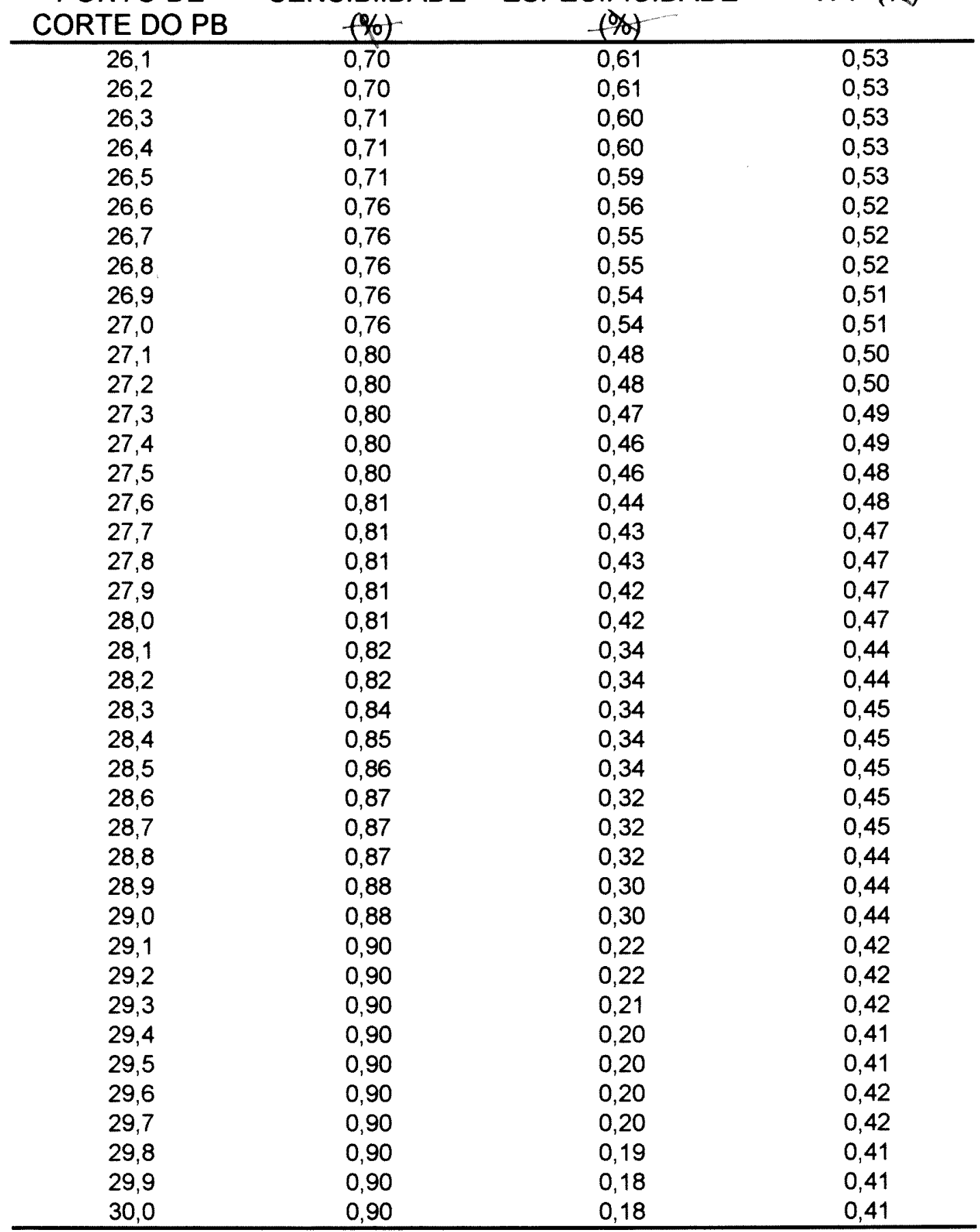


GRAFICO 1. RELAÇÃO ENTRE A ESPECIFICIDADE E SENSIBILIDADE NOS DIFERENTES PONTOS DE CORTE DO PB PARA PREDIZER PESO INADEQUADO AO NASCER $(\leq 3000)$

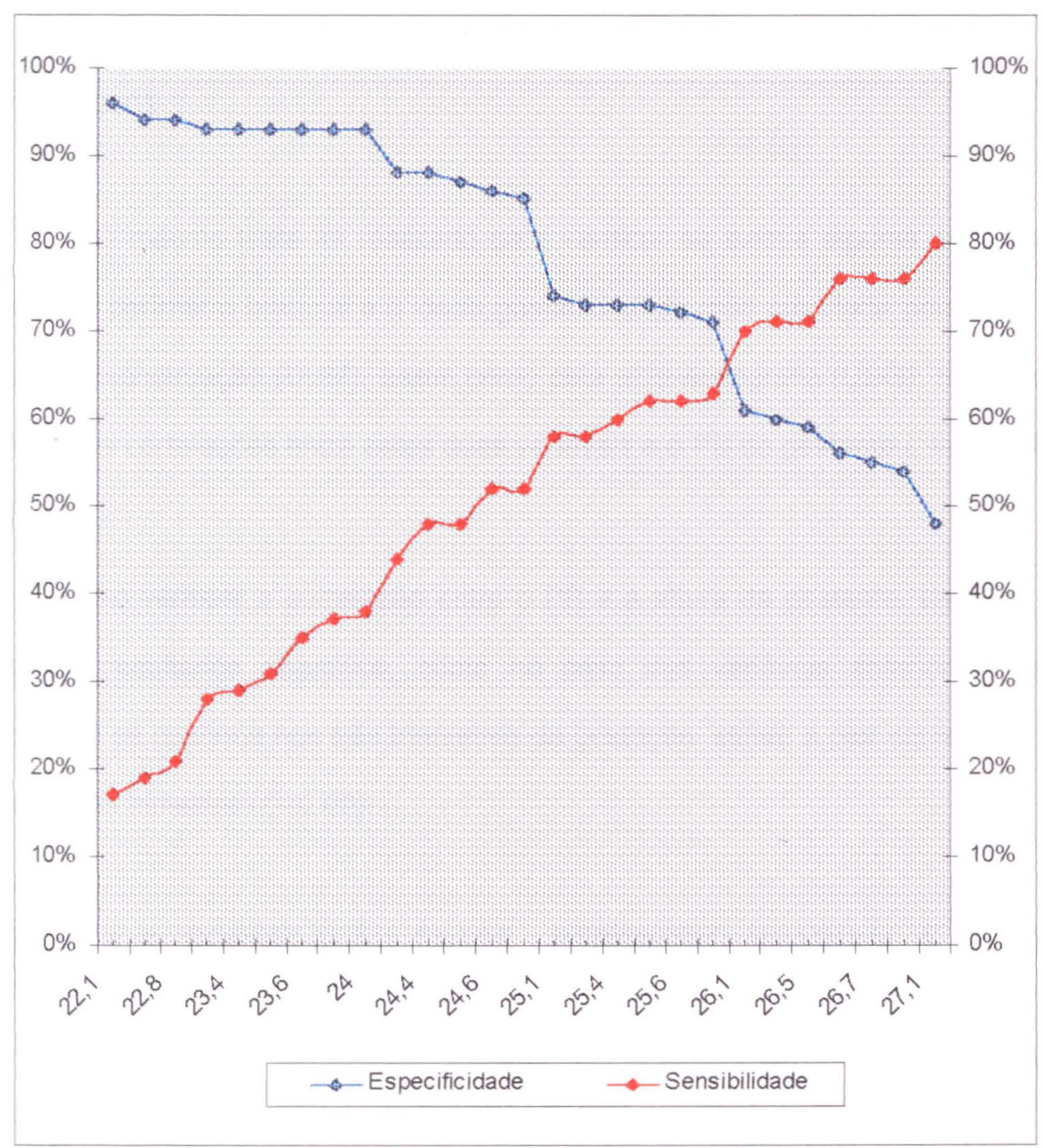


TABELA 7. CORRELAÇÃO E REGRESÃO LINEAR SIMPLES ENTRE PERÍMETRO BRAQUIAL E PESO DO RECÉM - NASCIDO $(\mathrm{N}=350)^{*}$

N COEFICIENTE COEFICIENTE INTERVALO DE

DE CORRELAÇÃO

DE REGRESÃO CONFIANÇA 95\%

\begin{tabular}{llll}
\hline 350 & $r=0,40$ & $r^{2}=0,16$ & $0.05-\cdots--0,26$ \\
\hline
\end{tabular}

${ }^{*} p<0,0001$

O mesmo teste foi realizado para verificar se existia alguma correlação entre o perímetro braquial e a idade gestacional da mãe calculada pela data da ultima menstruação (DUM), assim como pela ultra-sonografia (USG); não foram achados correlações entre estas duas variáveis e o PB da gestante ( ver tabelas 8, e 9).

Ao verificar a correlação entre o PB e a altura da gestante, também se obtém resultados negativos, como no caso das variáveis anteriores. Este achado se confirma nos três trimestres da gestação, sendo a pior correlação no segundo trimestre $\left(r^{2}=0.00\right)$.

TABELA 8. CORRELAÇÃO ENTRE PERÍMETRO BRAQUIAL E IDADE GESTACIONAL PELA DUM ( $N=350)$

\begin{tabular}{|c|c|c|c|c|}
\hline $\begin{array}{c}\text { TRIMESTRE } \\
\text { DA } \\
\text { GESTAÇÃO } \\
\end{array}$ & $N=350$ & $\begin{array}{c}\text { COEFICIENTE } \\
\text { DE } \\
\text { CORRELAÇÃO }\end{array}$ & $\begin{array}{c}\text { COEFICIENTE } \\
\text { DE } \\
\text { REGRESÃO } \\
\end{array}$ & $\begin{array}{c}\text { INTERVALO DE } \\
\text { CONFIANÇA } \\
95 \% \\
\end{array}$ \\
\hline I. Trimestre & 64 & $r=0,01$ & $r^{2}=0,00$ & $-0,19----0,21$ \\
\hline II. Trimestre & 142 & $r=0,04$ & $r^{2}=0,00$ & -0,08 -----0,16 \\
\hline III. Trimestre & 144 & $r=0,03$ & $r^{2}=0,00$ & -0,11-.--0,16 \\
\hline
\end{tabular}


TABELA 9. CORRELAÇÃO ENTRE PERÍMETRO BRAQUIAL E IDADE GESTACIONAL PELA USG $(\mathrm{N}=350)$

\begin{tabular}{ccccc}
\hline $\begin{array}{c}\text { TRIMESTRE } \\
\text { DA }\end{array}$ & $\mathbf{N}=350$ & $\begin{array}{c}\text { COEFICIENTE } \\
\text { DE } \\
\text { CORTEÇÃO }\end{array}$ & $\begin{array}{c}\text { COEFICIENTE } \\
\text { DE } \\
\text { REGRESÃO }\end{array}$ & $\begin{array}{c}\text { INTERVALO } \\
\text { DE } \\
\text { CONFIANÇA } \\
\mathbf{9 5 \%}\end{array}$ \\
\hline I. Trimestre & 64 & $r=0,33$ & $r^{2}=0,11$ & $-0,53-\ldots-0,66$ \\
II. Trimestre & 142 & $r=0,05$ & $r^{2}=0,00$ & $-0,27---0,28$ \\
III. Trimestre & 144 & $r=0,12$ & $r^{2}=0,02$ & $-0,41---0,45$ \\
\hline
\end{tabular}

Já ao testar a intensidade da associação entre o perímetro braquial e o peso da gestante, verifica-se uma correlação forte entre ambas variáveis $(r=0,75)$. Este achado já tinha sido verificado em estudos anteriores (HUFFMAN 1985; ANDERSON 1989; KRASOVEC 1989; RICALDE, 1994). Tal associação se apresenta mais forte no primeiro e segundo trimestre da gestação $(r=0,80$ e $r=0.78$ respectivamente).

No que diz respeito ao índice de massa corporal (IMC), também observou-se uma forte associação entre esta variável e o perímetro braquial. Os achados permanecem iguais quando se faz a análise por trimestres da gestação, verificando que, no segundo trimestre a associação é maior (de $r^{2}=0.61$ no teste geral, vai para $r^{2}=0.72$ no segundo trimestre). Estes achados são concordantes com os encontrados em outros estudos realizados em sete grupos diferentes de adultos de países em desenvolvimento. (WHO 1995). Os 
resultados das correlaçōes encontradas entre o perímetro braquial e o peso, altura, e IMC da gestante são apresentados na tabela 10 e 10.1 .

TABELA 10. CORRELAÇÃO E REGRESSÃO LINEAR SIMPLES ENTRE PERÍMETRO BRAQUIAL COM O PESO, ALTURA E IMC DA GESTANTE $(\mathrm{N}=350)$

\begin{tabular}{cccc}
\hline $\begin{array}{c}\text { VARIÁVEL } \\
\text { DE } \\
\text { CORRELAÇÃO }\end{array}$ & $\begin{array}{c}\text { COEFICIENTE } \\
\text { DE } \\
\text { CORRELAÇĀO }\end{array}$ & $\begin{array}{c}\text { COEFICIENTE } \\
\text { DE REGRESSÃO }\end{array}$ & $\begin{array}{c}\text { INTERVALO DE } \\
\text { CONFIANÇA } \\
\text { 95\% }\end{array}$ \\
\hline PESO & $r=0,75$ & $r^{2}=0,56$ & $0,49 \ldots-0,63$ \\
ALTURA & $r=0,09$ & $r^{2}=0,01$ & $-0,10 \ldots-0,11$ \\
IMC & $r=0,78$ & $r^{2}=0,61$ & $0,54 \ldots-0,68$ \\
\hline
\end{tabular}

TABELA 10.1. CORRELAÇÃO E REGRESSÃO LINEAR SIMPLES ENTRE PERÍMETRO BRAQUIAL COM O PESO, E IMC DA GESTANTE POR TRIMESTRES $(\mathbf{N}=350)$

\begin{tabular}{|c|c|c|c|c|}
\hline $\begin{array}{c}\text { TRIMESTRE } \\
\mathbf{N}\end{array}$ & $\begin{array}{l}\text { COEFICIENTE } \\
\text { DE } \\
\text { CORRELAÇÃO }\end{array}$ & $\begin{array}{l}\text { COEFICIENTE } \\
\text { DE } \\
\text { REGRESSÃO }\end{array}$ & $\begin{array}{c}\text { INTERVALO } \\
\text { DE } \\
\text { CONFIANÇA } \\
95 \% \\
\end{array}$ & $\begin{array}{c}\text { VARIÁVEL } \\
\text { DE } \\
\text { CORRELAÇÃO }\end{array}$ \\
\hline$I=64$ & $r=0,80$ & $r^{2}=0,56$ & 0,49 ----0,63 & PESO1 \\
\hline$\|=142$ & $r=0,78$ & $r^{2}=0,63$ & $0,49--0,63$ & PESO2 \\
\hline$I I I=144$ & $r=0,78$ & $r^{2}=0,63$ & $0,54---0,68$ & PESO3 \\
\hline$I=64$ & $r=0,83$ & $r^{2}=0,68$ & 0,53 ----0,80 & $\mathrm{IMC} 1$ \\
\hline$\|=142$ & $r=0,85$ & $r^{2}=0,72$ & $0,63--0,79$ & IMC2 \\
\hline III $=144$ & $r=0,79$ & $r^{2}=0,62$ & $0,51 \ldots 0,71$ & IMC3 \\
\hline
\end{tabular}


Apesar da boa sensibilidade, especificidade e valor preditivo positivo do perímetro braquial, para predizer risco de peso inadequado ao nascer, considerou-se nessário verificar o comportamento das outras variáveis maternas, e sua relaçao com o peso dos recém-nascidos que foram considerados de peso inadequado $(n=136)$. Desta maneira, procedeu-se ao cálculo das médias e desvios padroes do IMC, PB, peso do RN e altura da gestante. Os resultados são apresentados na Tabela 11.

Merece ser resaltado o fato de que os resultados das análisis feitas numa primeira fase onde são incluidas todas as gestantes, não sofreram alterações significativas quando se fazem as mesmas análisis (regressão, sensibilidade, especificidade e promedios gerais) no grupo das maes que tiveram seus recémnascido com peso inadequado $(<3000)$. Ou seja a exclusão ou inclusão deste grupo não alterou os resultados já encontrados.

TABELA 11. VALORES DO PB, ALTURA, IMC, DAS GESTANTES QUE TIVERAM RECÉM-NASCIDO COM PESO INADEQUADO ( $\leq 3000$ ) n=136

\begin{tabular}{cccccc}
\hline VARIAVEL & MEDIA & DP & MEDIANA & $\mathbf{2 5 \%}$ & $\mathbf{7 5 \%}$ \\
\hline PB $(\mathrm{cm})$ & 25,1 & 3,0 & 24,5 & 23,0 & 26.5 \\
ALTURA $(\mathrm{cm})$ & 158,0 & 6,2 & 157,0 & 154,0 & 162,0 \\
IMC $\left(\mathrm{kg} / \mathrm{m}^{2}\right)$ & 24,3 & 3,8 & 23,6 & 21,3 & 27,0 \\
PESO RN $(\mathrm{g})$ & 2716,0 & 199,5 & 2730,0 & 2607,0 & 2870,0 \\
\hline
\end{tabular}


Os achados permitem inferir que, trata-se de mulheres não baixas, com a estatura média ligeiramente acima da média da população brasileira $(156,3 \pm 6,4$ - média da estatura para 1996, NUPENS/USP 1997); com IMC adequado, no entanto com PB pequenos $(67,6 \%$ apresentam $P B<24,5)$. Sendo assim, fica para responder a questão: porque estas mulheres que têm em media "boas reservas" energeticas, tiveram filhos com pesos inadequados?. Sendo que destes $75,8 \%$ tiveram seus pesos inferiores, (menor de 2870 gramas), a média do peso do RN no primeiro quintil (considerado o menor).

Passou-se então a verificar a relação entre o IMC eo PB neste grupo de muheres, levando em consideração o limite proposto no informe da OMS (WHO 1995), para mulheres não gestantes, onde um PB de $24 \mathrm{~cm}$ corresponde a um IMC <18.5. Constata-se que, nesta população de gestantes, tal relação não existe a rigor, já que, do total das 86 gestantes que tiveram PB menor de $24 \mathrm{~cm}$, em apenas nove casos (10.1\%) os valores de IMC são menores de 18.5 . E em relação as gestantes que tiveran seus $R N$ com peso inadequado $(n=136)$, somente em quatro casos ( $3 \%$ ) o IMC menor corresponde a um PB menor. E no caso do caso do peso inferior a $2500 \mathrm{~g}$ só uma mãe apresentou IMC menor de 18.5

Estes achados permitem inferir que, o Indice de Massa Corporal em gestantes, não parece ser o melhor indicador para predizer peso inadequado. É preciso mencionar que, o peso da gestante varia durante a gravidez, enquanto que a estatura permanece a mesma, ambas variáveis utilizadas para o calculo 
do IMC. Também é conhecido que, o indice de massa corporal representa as reservas nutricionais, ou seja o sobrepeso ou a magreza do indivíduo.

No entanto, ainda não esta claro quanto de essas reservas ficaram para a mãe e quanto para o feto, poder-se-ia inferir que os limites do IMC para classificar as mulheres não gestantes, não levam em consideração o peso do RN, em consequencia precisam ser estabelecidos os limites do Indice de Massa Corporal na gestação, para de esta maneira avaliar se a gestante esta apresentando problemas de emagrecimento ou sobrepeso, fatores que estariam alterando seu estado nutricional e de saúde, e por tanto poderiam interferir no resultado da gestação. Fica então discutivel o uso do IMC associado ao PB como indicador de risco de recém nascido com peso inadequado ao nascer ou de baixo peso.

Deve-se lembrar que, entre os fatores de risco maternos, conhecidos como fatores relacionados diretamente ao baixo peso ao nascer (patologias placentarias, DHEG, vicios nocivos como drogas, alcóol, entre outros), evidenciou-se presença de tabagismo em apenas $10,9 \%$ e somente $2,8 \%$ das mesmas fumam mais de cinco cigarros por dia. Portanto o que se procura é verificar se há uma situação materna relacioanada ao seu estado corporal que poderia levar a desencadear um $\mathrm{RN}$ de peso baixo ou neste caso inadequado.

Levando em consideração os resultados até agora obtidos, considerou-se interessante explorar a variável estatura materna, devido a que os achados 
anteriores induzem a pensar que poderiam ser mulheres ligeiramente "altas" e "magras", porém sadias. Passou-se a verificar esta relação.

Observou-se que $52,2 \%$ destas gestantes, com RN de peso inadequado, apresentaram perimetros braquiais pequenos $(<24,5 \mathrm{~cm}=$ ponto de corte para peso inadequado), ao mesmo tempo tinham IMC considerados normais (média do $I M C=24$ ), mas com estaturas discretamente maiores (estatura média=158 $\mathrm{cm})$ do que a média da população brasileira $(156,3 \mathrm{~cm})$. Pensou-se que, esta poderia ser a condição, pela qual estas mulheres tiveram seus RN com peso inadequado.

De esta maneira, passou-se a calcular um índice baseado no perimetro braquial da gestante e sua estatura [(PB/altura $\left.)^{\star} 100 \%\right]$, que foi chamado de "Índice Ricalde-Siqueira", cujo principal objetivo era verificar se estas duas variáveis associadas, seriam capazes de predizer o risco da gestante ter um RN com peso inadequado ao nascer $(<3000)$.

No anexo 1 apresenta-se a lista dos indices obtidos para cada gestante deste estudo. A média desta variável foi de $16,7( \pm 2,1)$ e a mediana ficou em 16,5. A distribuição das gestantes de acordo com o indice calculado, assim como a média do peso do recém-nascido correspondentes a tais indices, são apresentados na Tabela 12 . 


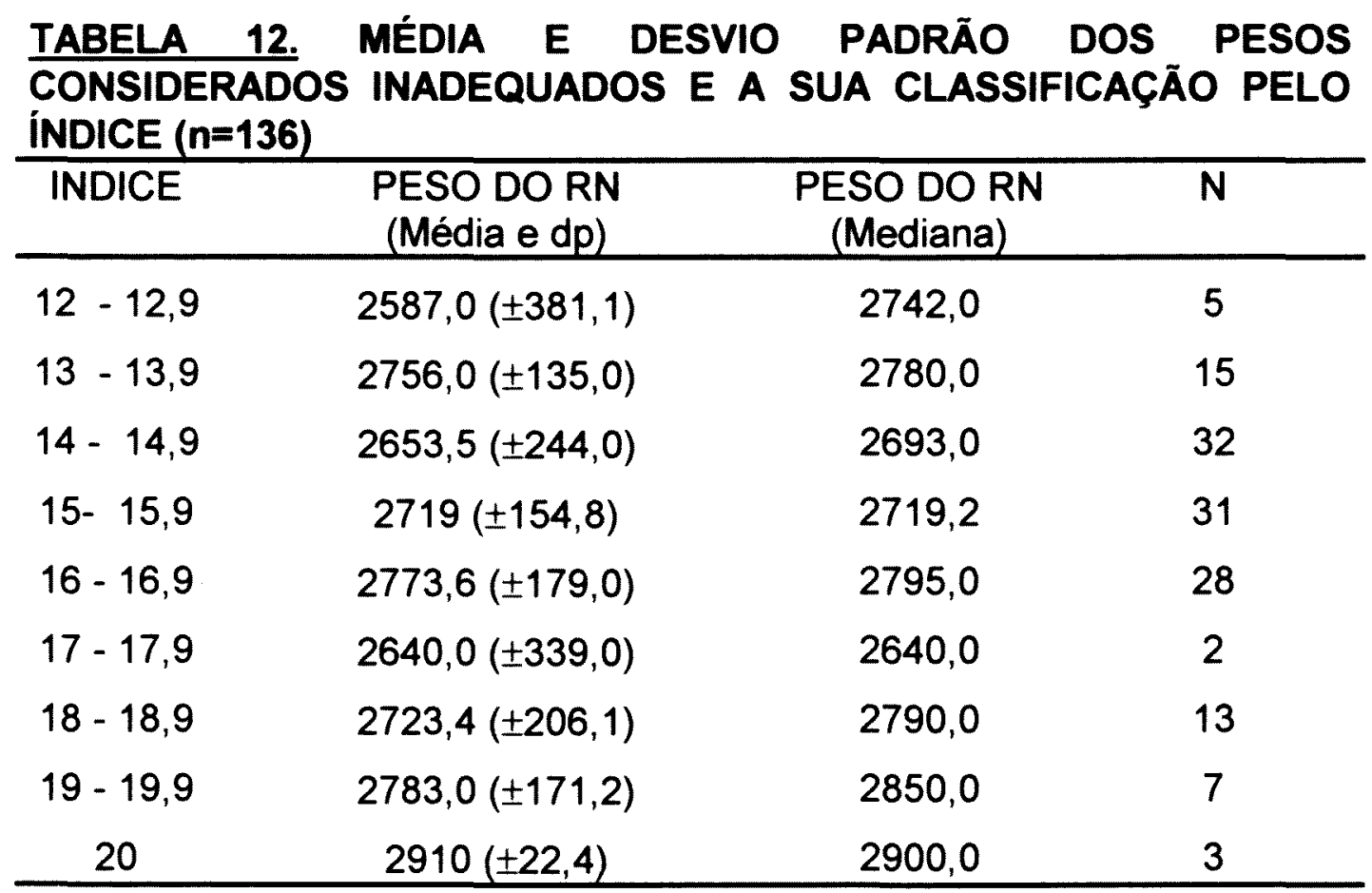

Após vários testes de sensibilidade e especificidade e valor preditivo, ficou estabelecido que o melhor indicador de peso inadequado era igual ou menor ao indice de 15,1 (ver tabelas 13a e 13b), este valor apresenta uma sensibilidade de $39 \%$, uma especificidade de $87 \%$ com um valor preditivo positivo (VPP) de 65\% para predizer peso inadequado do recém-nascido (s $3000)$. 
TABELA 13a. SENSIBILIDADE, ESPECIFICIDADE E VPP DO INDICE RICALDE-SIQUEIRA (PBIALTURA) EN DIFERENTES PONTOS DE CORTE PARA PREDIZER PESO INADEQUADO AO NASCER $(\leq 3000)$

\begin{tabular}{|c|c|c|c|}
\hline $\begin{array}{l}\text { PONTO DE CORTE DO } \\
\text { INDICE }\end{array}$ & $\begin{array}{c}\text { SENSIBILIDADE } \\
(\%)\end{array}$ & $\begin{array}{c}\text { ESPECIFICIDADE } \\
(\%)\end{array}$ & $\begin{array}{l}\text { VPP } \\
(\%)\end{array}$ \\
\hline 12,0 & 0,00 & 0,99 & 0,00 \\
\hline 12,1 & 0,00 & 0,99 & 0,00 \\
\hline 12,2 & 0,00 & 0,99 & 0,00 \\
\hline 12,3 & 0,00 & 0,99 & 0,00 \\
\hline 12,4 & 0,01 & 0,00 & 0,33 \\
\hline 12,5 & 0,01 & 0,99 & 0,33 \\
\hline 12,6 & 0,01 & 0,99 & 0,50 \\
\hline 12,7 & 0,01 & 0,99 & 0,50 \\
\hline 12,8 & 0,01 & 0,99 & 0,40 \\
\hline 12,9 & 0,02 & 0,99 & 0,50 \\
\hline 13,0 & 0,04 & 0,99 & 0,63 \\
\hline 13,1 & 0,04 & 0,98 & 0,56 \\
\hline 13,2 & 0,05 & 0,98 & 0,64 \\
\hline 13,3 & 0,98 & 0,62 & 0,00 \\
\hline 13,4 & 0,06 & 0,96 & 0,50 \\
\hline 13,5 & 0,08 & 0,96 & 0,55 \\
\hline 13,6 & 0,10 & 0,96 & 0,59 \\
\hline 13,7 & 0,10 & 0,96 & 0,59 \\
\hline 13,8 & 0,10 & 0,93 & 0,48 \\
\hline 13,9 & 0,12 & 0,95 & 0,62 \\
\hline 14,0 & 0,13 & 0,95 & 0,62 \\
\hline 14,1 & 0,15 & 0,94 & 0,64 \\
\hline 14,2 & 0,20 & 0,94 & 0,68 \\
\hline 14,3 & 0,24 & 0,94 & 0,71 \\
\hline 14,4 & 0,26 & 0,93 & 0,69 \\
\hline 14,5 & 0,26 & 0,93 & 0,69 \\
\hline 14,6 & 0,28 & 0,91 & 0,66 \\
\hline 14,7 & 0,31 & 0,91 & 0,68 \\
\hline 14,8 & 0,33 & 0,90 & 0,67 \\
\hline 14,9 & 0,34 & 0,88 & 0,65 \\
\hline 15,0 & 0,35 & 0,87 & 0,64 \\
\hline 16,1 & 0,38 & 0,87 & 0.60 \\
\hline 15,2 & 0,40 & 0,86 & 0,64 \\
\hline 15,3 & 0,42 & 0,85 & 0,63 \\
\hline 15,4 & 0,44 & 0,84 & 0,64 \\
\hline 15,5 & 0,47 & 0,81 & 0,62 \\
\hline 15,6 & 0,79 & 0,59 & 0,00 \\
\hline 15,7 & 0,49 & 0,78 & 0,59 \\
\hline 15,8 & 0,52 & 0,76 & 0,58 \\
\hline 15.9 & 0,55 & 0.74 & 0,57 \\
\hline
\end{tabular}


TABELA 13b. SENSIBILIDADE, ESPECIFICIDADE E VPP DO INDICE RICALDE-SIQUEIRA (PBIALTURA) EN DIFERENTES PONTOS DE CORTE PARA PREDIZER PESO INADEQUADO AO NASCER $(\leq 3000)$

\begin{tabular}{|c|c|c|c|}
\hline $\begin{array}{l}\text { PONTO DE CORTE } \\
\text { DO INDICE }\end{array}$ & $\begin{array}{c}\text { SENSIBILIDADE } \\
(\%) \\
\end{array}$ & $\begin{array}{l}\text { ESPECIFICIDADE } \\
(\%)\end{array}$ & $\begin{array}{l}\text { VPP } \\
(\%)\end{array}$ \\
\hline 16,0 & 0,57 & 0,71 & 0,55 \\
\hline 16,1 & 0,60 & 0,69 & 0,55 \\
\hline 16,2 & 0,62 & 0,68 & 0,55 \\
\hline 16,3 & 0,65 & 0,67 & 0,56 \\
\hline 16,4 & 0,65 & 0,64 & 0,54 \\
\hline 16,5 & 0,68 & 0,62 & 0,53 \\
\hline 16,6 & 0,70 & 0,59 & 0,52 \\
\hline 16,7 & 0,71 & 0,58 & 0,52 \\
\hline 16,8 & 0,73 & 0,57 & 0,52 \\
\hline 16,9 & 0,75 & 0,54 & 0,51 \\
\hline 17,0 & 0,75 & 0,53 & 0,50 \\
\hline 17,1 & 0,76 & 0,49 & 0,49 \\
\hline 17,2 & 0,77 & 0,47 & 0,48 \\
\hline 17,3 & 0,78 & 0,45 & 0,47 \\
\hline 17,4 & 0,79 & 0,50 & 0,50 \\
\hline 17,5 & 0,79 & 0,42 & 0,46 \\
\hline 17,6 & 1,00 & 0,39 & 0,51 \\
\hline 17,7 & 0,82 & 0,39 & 0,46 \\
\hline 17,8 & 0,83 & 0,37 & 0,46 \\
\hline 17,9 & 0,83 & 0,35 & 0,45 \\
\hline 18,0 & 0,85 & 0,34 & 0,45 \\
\hline 18,1 & 0,85 & 0,31 & 0,44 \\
\hline 18,2 & 0,00 & 0,85 & 0,28 \\
\hline 18,3 & 0,86 & 0,27 & 0,43 \\
\hline 18,4 & 0,87 & 0,25 & 0,42 \\
\hline 18,5 & 0,87 & 0,23 & 0,42 \\
\hline 18,6 & 0,88 & 0,21 & 0,42 \\
\hline 18,7 & 0,89 & 0,21 & 0,42 \\
\hline 18,8 & 0,90 & 0,19 & 0,41 \\
\hline 18,9 & 0,91 & 0,16 & 0,41 \\
\hline 19,0 & 0,93 & 0,16 & 0,41 \\
\hline 19,1 & 0,94 & 0,14 & 0,41 \\
\hline 19,2 & 0,93 & 0,13 & 0,41 \\
\hline 19,3 & 0,93 & 0,12 & 0,40 \\
\hline 19,4 & 0,94 & 0,11 & 0,40 \\
\hline 19,5 & 0,94 & 0,10 & 0,40 \\
\hline 19,6 & 0,95 & 0,09 & 0,40 \\
\hline 19,7 & 0,95 & 0,09 & 0,40 \\
\hline 19,8 & 0,96 & 0,09 & 0,40 \\
\hline 19,9 & 0,96 & 0,08 & 0,40 \\
\hline 20,0 & 0,96 & 0,08 & 0,40 \\
\hline
\end{tabular}


Quando se realiza o teste de regressão linear simples, verifica-se que o indice apresenta uma intensidade de associação com o peso do recém-nascido em torno de $37 \%(r=0,37)$ e as variações deste índice explicariam $13 \%$ das variações do peso do recém-nascido $\left(r^{2}=0,13\right)$. Quando se verificam as associações entre o índice e o baixo peso ao nascer $(<2500)$, os resultados são melhores do que os anteriores, assim o indice apresenta uma correlação relativamente alta $(r=0,54)$ e explica em $29 \%$ as variaçòes que ocorrem no baixo peso ao nascer.

Com esta verificação passou-se a construir uma curva de referencia em função do "índice", para para as diferentes idades da mulher em idade fértil. Para tal efeito foi utilizado o programa "Curve Expert", o qual permite estimar a estatura e o perímetro braquial correspondentes aos diferentes níveis do índice.

Assim obteve-se três curvas para os indices 16,14 e 12; para o indice menor ou igual a 16, o modelo que melhor explica a curva foi o "Saturation growth - rate model", com um erro padrão de 0.58 e um coeficiente de correlação proximo de $1(r=0.99919)$. Para o indice menor ou igual a 14 o melhor modelo de curva foi o de "Hoerl" com um erro padrão de 0.23 e um coeficiente de correlação também próximo de $1(r=0.99998)$. Para o indice igual ou menor de 12, o melhor ajuste da curva foi com o modelo de "Rational function", com um erro padrão de 0.50 e um coeficiente de correlação igual a 0.9999 . Os modelos das curvas são mostrados em anexo 2 , com suas respectivas formulas. 
Para sua utilização prática passou-se a construir um gráfico com as três curvas onde se considerou que o indice menor de 16 seria o risco leve de peso inadequado ao nascer, o indice igual ou menor de 14 considerou-se risco moderado e o indice menor ou igual a 12 risco grave de ter um recém-nascido com peso inadequado $(\leq 3000)$. Ver grafico 2 .

Posteriormente foi verificado quantos casos dos estudados estarian dentro de esta curva proposta, foram encontrados 75 casos correspondendo aos diferentes níveis do indice, desde o indice 12 até o 16. Para melhor ilustração apresenta-se a tabela 14 .

TABELA 14. MÉDIA E DESVIO PADRÃO DOS PESOS CONSIDERADOS INADEQUADOS (<3000) CORRESPONDENTES AOS INDICES MENORES DE $16 \quad(n=75)$

\begin{tabular}{rcc}
\hline INDICE & PESO DO RN (Média dp) & N \\
\hline $12-12,9$ & $2562,0( \pm 383,0)$ & 4 \\
$13-13,9$ & $2740,0( \pm 125,0)$ & 14 \\
$14-14,9$ & $2619,0( \pm 232,0)$ & 29 \\
$15-15,9$ & $2685,0( \pm 11,0)$ & 28 \\
\hline
\end{tabular}

Deve se levar em consideração que, a curva proposta é resultado das estimativas matemáticas realizadas em função do Índice, considerado indicador de peso inadequado ao nascer $(<3000 \mathrm{~g})$. Sugere-se validar este instrumento com uma amostra de gestantes mais representativa da população brasileira ou qualquer outra população que se deseje estudar. 
Finalmente, foram comparados os testes de associação obtidos para o perímetro braquial menor ou igual a $24,5 \mathrm{~cm}$ (ponto de corte escolhido para diagnóstico de risco de PIAN) e o índice menor ou igual a 15, ponto de corte que estaria, também indicando risco de peso inadequado ao nascer. Assim verificase que o perímetro braquial materno apresenta um odds ratio maior do que o índice, e um risco relativo ligeiramente melhor do que o indice pb/altura. Para ilustração apresenta-se a tabela 15 .

TABELA 15. ODDS RATIO E RISCO RELATIVO DO PERIMETRO BRAQUIAL E O INDICE PBIALTURA DA GESTANTE, PARA PREDIZER PESO INADEQUADO AO NASCER $(<3000) \mathrm{N}=136$

\begin{tabular}{|c|c|c|c|}
\hline VARIÁVEL & ODDS RATIO & $\mathrm{RR}^{*}$ & $p^{\star \star}$ \\
\hline \multirow{2}{*}{$\begin{array}{c}\mathrm{PB} \leq 24,5 \\
\mathrm{~cm}\end{array}$} & 5,71 & 2,43 & $<0,000000$ \\
\hline & $(3,33-9,82)$ & $(1,92-3,07)$ & \\
\hline \multirow{2}{*}{$\begin{array}{c}\text { Indice } \\
\text { pb/altura } \\
\leq 15,0\end{array}$} & 3,60 & 2,21 & $<0,0000001$ \\
\hline & $(2,08-6,23)$ & $(1,61-2,67)$ & \\
\hline
\end{tabular}


GRAFICO 2. INDICE RICALDE-SIQUEIRA (PB/ESTATURA) PARA PREDIZER RISCO DE PESO INADEQUADO AO NASCER (PIAN) $(\leq 3000)$

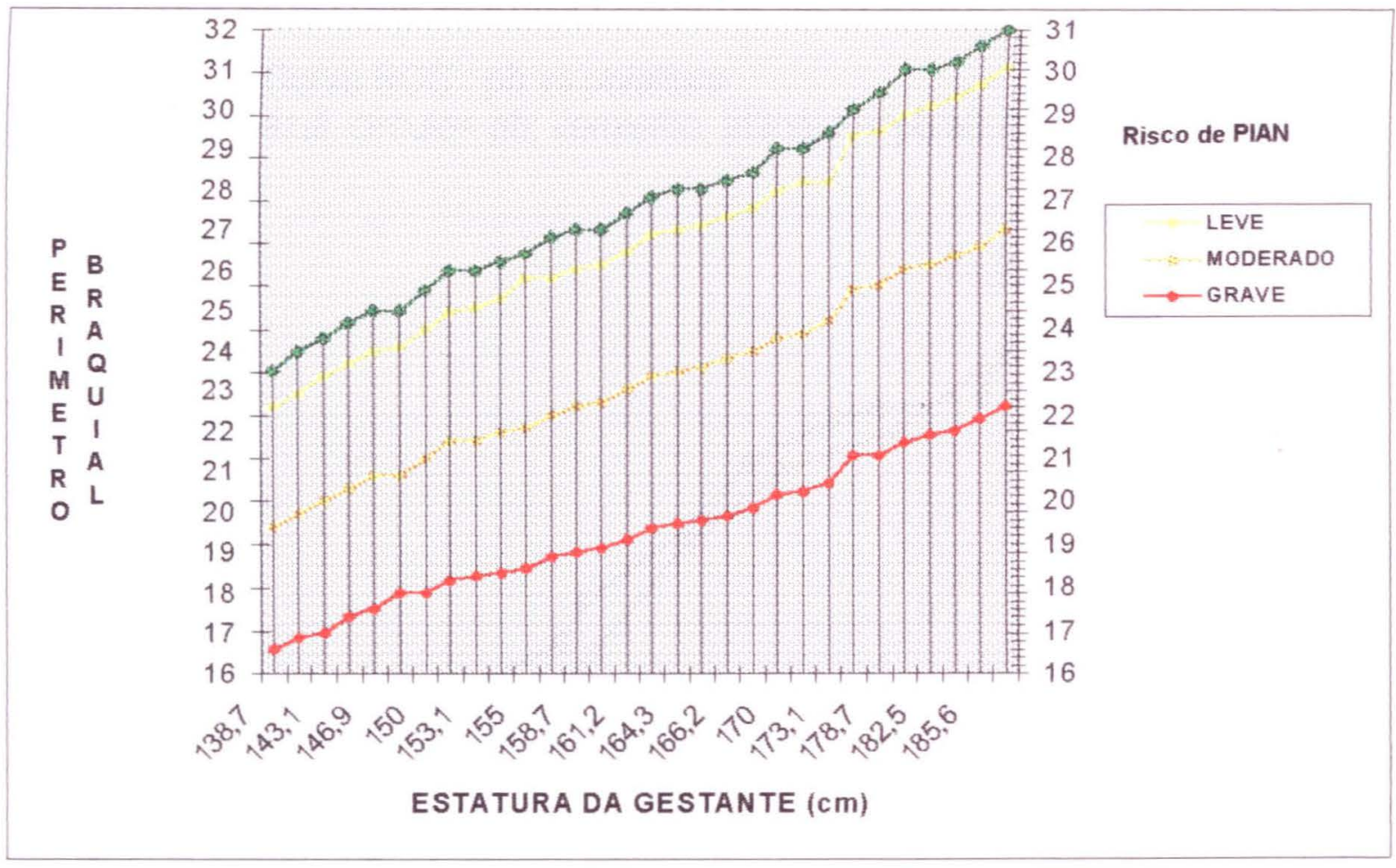

Por último foi construida a curva ROC (Receveing operator charactheristic) para ilustrar melhor a relação da especificidade e sensibilidade, tanto do perímetro braquial materno e o indice pb/altura como preditores do risco de peso inadequado ao nascer. Ambas curvas são semelhantes. A área do PB na curva ROC é um pouco maior $\left(7182,8 \mathrm{~m}^{2}\right)$ do que a área do indice pb/altura, sendo esta última de $6856,4 \mathrm{~m}^{2}$. Ambos indicadores apresentam valores que permitem considera-los adequados para predizer peso ao nascer, e, no caso do presente estudo, peso inadequado ao nascer. 
GRAFICO 3.- CURVA ROC PARA A SENSIBILIDADE E ESPECIFICIDADE DO PB E O INDICE PBIALTURA EM DIFERENETS PONTOS DE CORTE PARA PREDIZER PESO INADEQUADO AO NASCER (<3000 g)

Curva ROC : pb vs pb/altura

azul, círculo= pb; vermelho, triângulo= pb/altura

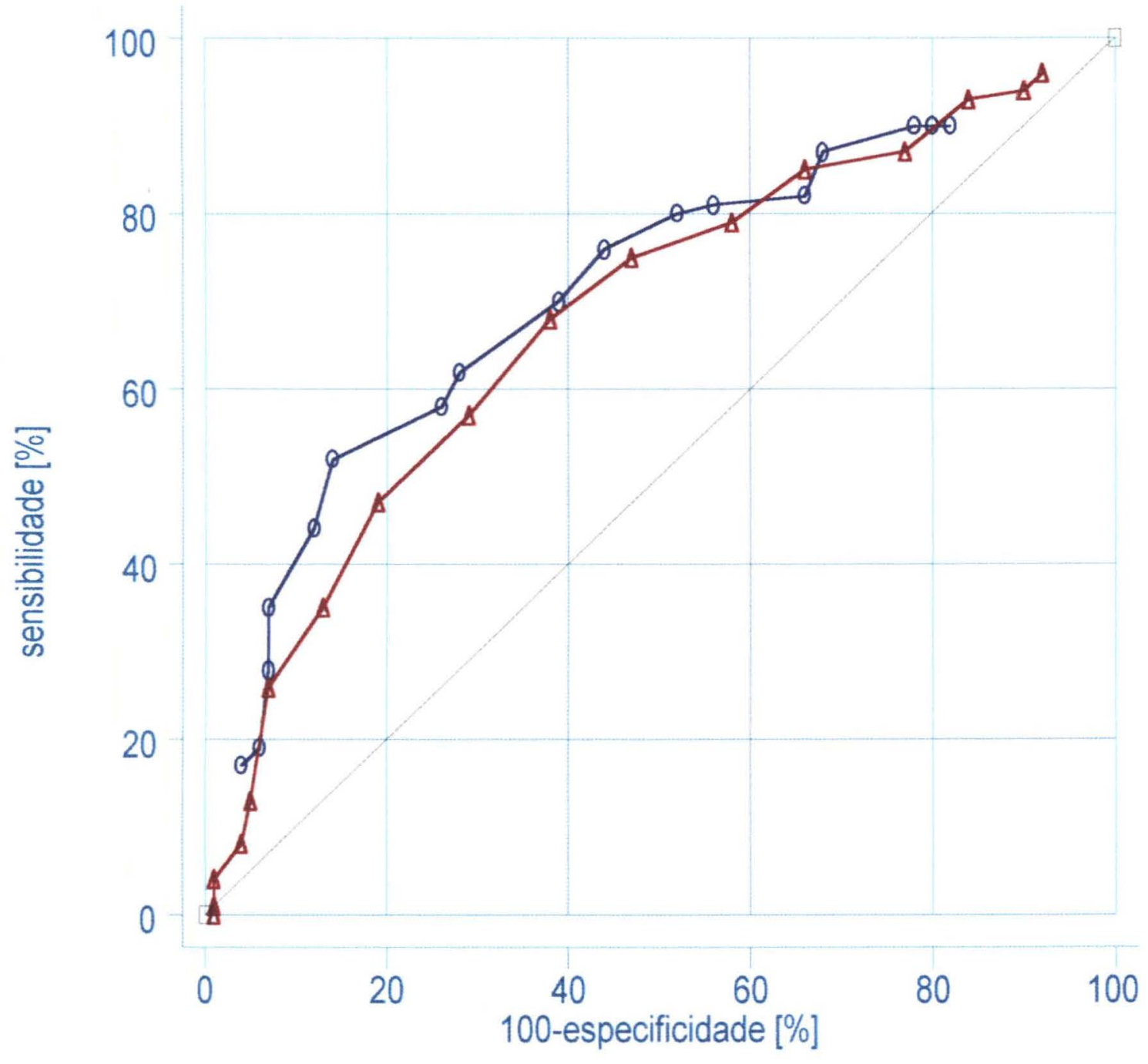


CONCLUSÕES 


\section{CONCLUSÕES}

Os resultados obtidos neste estudo permitem as seguintes conclusões:

- O perímetro braquial materno esta fortemente correlacionado com o peso da gestante e o Índice de Massa Corporal em qualquer trimestre da gravidez (Tabela 10), a associação entre estas variáveis é independente da idade gestacional. Este achado permite inferir que $e_{\mu}$ as mudanças que ocorrem no peso e nas reservas nutricionais maternas 'vão se traduzir em mudanças da medida do braço. Este fato permite sugerir o uso do perímetro braquial no lugar da informação do peso pré-gestacional, quando a mulher não sabe referir seu peso anterior a gravidez, e no lugar da informação do peso gestacional quando a pesagem da gestante não é viável.

- O perímetro braquial menor ou igual a $23,5 \mathrm{~cm}$ apresenta boa sensibilidade e especificidade para predizer risco de baixo peso ao nascer, dados que são concordantes com os achados em pesquisas anteriores no Brasil (WHO,1995). Apesar de que a prevalência de baixo peso ao nascer nesta população foi apenas de $5,7 \%$, muitas mulheres que realmente estão precisando se beneficiariam das intervenções nutricionais, já que a especificidade deste indicador é alta (83\%).

- A proporção de recém-nascidos com peso inadequado $(<3000 \mathrm{~g})$ foi superior $(39,0 \%)$ a tendência observada pela Fundação SEADE $(35,4 \%)$. 
- O melhor ponto de corte do perimetro braquial, para predizer risco de peso inadequado ao nascer ( $<3000 \mathrm{~g}$ ), esta em $24,5 \mathrm{~cm}$ com boa sensibilidade (48\%), especificidade (87\%) e valor preditivo positivo (71\%).

- $O$ índice Ricalde-Siqueira (perímetro/estatura) $<15,1$ proposto neste estudo, mostrou-se como bom preditor do peso inadequado ao nascer, com elevada especificidade ( $87 \%$ ), elevado valor preditivo positivo $(65 \%)$ e boa sensibilidade $(39 \%)$.

- As medições do perímetro braquial e, as estimativas do Índice perímetro braquial / estatura maternos, podem ser considerados alternativas práticas para o diagnóstico do risco de peso inadequado ao nascer. Fica a proposta do Índice para ser validada em populações mais representativas, e desta maneira poder estabelecer os valores limites, que possam predizer com mais precisão o risco de uma gestação não favorável em termos do peso do recém-nascido. 


\section{REFERÊNCIAS}

Anderson, M A. The relationship between maternal nutrition and child growth in rural India; 1989. [PH. D. Dissertation - Tufts University].

Arisoy AE. e Sarman G. Chest and Mid-Arm Circunferences: Identification of low birth weight Newborns m Turkey. J. Trop. Peditr feb 1995; 41(1): 34-7.

Bergner L. e Susser MW. Low birth weight and prenatal nutrition: an interpretative review. Pediatrics 1970; 46: 946-66.

Bishop C. e Pitchey SJ. Estimation of mid-upper arm circumference measurement error. J AM. Diet. Assoc 1987; 469 - 73.

Bissenden JG, Scott PH, King J, Hallun J, Mansfield HN, e Wharton BA. Anthropometric and biochemical changes during pregnancy in asian and european mothers having well babies. Br. J Obstet. Gynaecol 1981; 88: 992 - 8.

Briend A. Fetal stunting, fetal wasting and maternal nutritional status. In : Aebi H. e Whitehead RG, editors. Maternal nutrition during pregnancy and lactation. Bem, Hans Huber Press, 1980. p. 150 - 9.

Bull.World Health Organ. Use of a simple anthropometric measurement to predict birth weight. WHO Collaborative Study of birthi weight surrogates. Bulletim OMS 1993; 71(2): 157-63. 
Bull World Health Organization. Maternal anthropometry and pregnancy outcomes. A WHO Collaborative Study. Bulletim OMS 1995; 73: I-98 [Suppl].

Desai ID et al. Food habits and nutritional status of agricultural migrant workers in southern Brazil. Am J Clin. Nutr 1980; 33: 702-714.

Frisancho AR, Klayman JE e Matos J. Influence of maternal nutritional status on prenatal growth in a Peruvian Urban Population. Am. J. Clin. Anthrop 1977(a); 46: 265-274.

Ferro-Luzzi A e James WP. Adult malnutrition: simple assessment techniques for use in emergencies. $\mathrm{Br}$. J. Nutr. 1996; 75(1): 3-10.

ueri $M$, Jutsum $P$, Sorhaindo $B$. Anthropometric assesment of nutritional status in pregnant women. AM. J. Clin. Nutr 1982; 35:609-16.

Fundação das Nações Unidas para a Infância. A infancia brasileira nos anos 90. Brasilia, 1998.

Huffman SL, Krasovec MA. Maternal nutritional risk assesment [For presentation at the XIII International Congress of Nutrition; $198518-23^{\text {rd }}$ August; Brighton UK.

Hull VJ. The Ngaglik study, an inquiry into birth interval dynamics and maternal and child health in rural Java. World Health Stat. Q 1983; 36: 100 $-18$.

Husaini YK, Husaini MA, Sulaiman Z, Jahari AB, Barizi, Hudono ST, et al. Maternal malnutrition, outcome of pregnancy, and a simple tool to identify women at risk. Food and Nutr. Bull; 1986. v. 8, n. 1, p. 71-78. 
Hytten F, Leitch I. The phisiology of human pregnancy, 2nd ed. London, 1971. Oxford University Press,

Jansen A.AJ, Kusin JA, Thiuri B, Lakhani AS, Mannetje W. Machakos project studies no. XXIVG. Anthropometric changes during pregnancy in rural african women. Trop. Geogr. Med 1984; 36 : 91-7.

Jere $\mathrm{DH}$. Weight gain in pregnancy. In:. Maternal Nutrition and pregnancy outcomes: anthropometric assesment. Krasovec, $K$ and Anderson, M.A., ed. Washington. Pan.American Health Organization, 1991. p. 29-51. (PAHO Scientific Publications, 529).

JOHNSON et al. Dietary intakes, Anthropmetrics Measurements and Pregnancy Outcomes. J. Nutr 1994; jun. 124 (6 suppl): 936S-942S.

Kardjati S, Kusin JA, Schofield WM, de With C. et al. Energy suplementation in the last trimester of pregnancy in East Java: Effect on maternal anthropometry. Am. J. Clin. Nutr. 1990; 52: 987-94.

Khan LK, Harrison GG, Galal OM, Ritenbaugh CH, Shaheen FM, Kirsey A et al. Prevalence and functional correlates of obesity in an egyptian village. Ecologv of Food and Nutrition 1996; 34: 311-325

Kramer M. Determimants of low birth weight: methodological assesment and meta-analysis. Bull. WHO; 1987. v. 65, n. 5, p. 663-737.

Krasovec K. An investigation into the use of maternal arm circunference for nutritional monitoring of pregnant women. 1989, [Sc. Dissertation School of Higiene and Public Health, Johns Hopkins University]. 
Krasovec K. Arm circunference, background issues, chapter 10 In: Maternal nutrition and pregnancy outcomes: anthropometric assesment. Editors Krasovec K, Anderson MA. PAHO, 1991 [scientific publication $N^{\circ}$ 529].

Krasovec K, Anderson MA. Maternal nutrition and pregnancy outcomes: anthropometric assesment. Washington (DC): Pan American Health Organization, 1991. (PAHO scientific publication, $\mathrm{N}^{\circ} 529$ ).

Lechtig A. Predicting risk of delivering low birth weight babies: wich indicator is better?. J.Trop. Pediatr; 1988. n. 34, p. 34-41.

Lee W, Comstock CH, Kirk JS, Smith RS, Monck JW, Deenadayalu R. et al. Birthweight prediction by three-dimensional ultrasonographic volumes of the fetal thigh and abdomen. J.Ultrasound.Med.1997; 16:799-805.

Masso MJ, Gong EJ, Jacobson MS, Bross DS, Heald FP. Anthropometric predictors of low blrth weight. Outcome in teenage pregnancy. Journal of Adolescent Health Care, 1988; 9: 188-93.

Monteiro CA, Benicio D'aquino MH, Martins de Freitas IC. Melhoria em indicadores de saúde associados à pobreza no Brasil dos anos 90: descrição, causas e impacto sobre desigualdades regionais. São Paulo; NUPENS/USP; 1997.

Naeye R. Weight gain and the outcome of pregnancy. AM. J Obstet. Gynecol., 1979; 135(1): 3-9.

Neel NR, Alvarez JO. Risk factors of fetal malnutrition in a group of guatemalan mothers and neonates. Bol. Oficina Sanit. Panam. 1991; 110 : 93-107. 
Niswander K, Jackson EC. Physical characteristics of the gravida and their association with birth weight and perinatal death. Am. J. Obst. Gynecol. 1974; 119: 306-10.

Olukoya AA, Giwa OF. Maternal weight and weight gain during pregnancycan the arm circunference be used as surrogate?. Afr. J. Med. Sci., 1991; 20:155-62.

Ott WJ. Intrauterine growth retardation and preterm delivery. Am. J. Obstet. Gynecol. 1993; (168): 1710-5.

Pastoral da criança. Guia do líder comunitario. $24^{\mathrm{a}}$ ed. Brasilia, 1997.

Palo P, Erkkola R. Risk factors and deliveries with preterm, severely small for gestational age fetuses Am. J. Perinatol. 1993; (10): 88-91.

Ricalde $A E$. Contribuição para o estudo do perímetro braquial na avaliação do estado nutricional da gestante. São Paulo; 1994 [Tese de Mestrado - Faculdade de Saúde Pública da USP].

Ricalde AE, Velasquez-Melendez G, Tanaka AC d'A, Siqueira AAF de. Mid arm circumference in pregnant women and its relation to birth weight. Rev. Saúde Pública 1998; 32 (2): 112-7.

Rosso P. A new chart to monitor weight gain during pregnancy. Am. J. Clin. Nutr. $1985 ; 41: 644-52$.

Rush D, Davis H, Susser M. Antecedents of low birth weight in Harlem, New York City. Int. J. Epidemiol. 1972; (1): 375-387. 
Shah A. Apropriate technology and perinatal care: The kasa experience. Adv. Int Maternal Child Health 1982; (2): 1-15.

Shah $\mathrm{K}$. The evolution of the use of arm circunference for assesing maternal nutritional status. In: Maternal nutrition and pregnancy outcomes. Anthropometric assesment. 1991; 132-137.

Siqueira AAFde. Estudo de um conjunto de curvas antropométricas no diagnóstico de estado nutricional e sua relação com o tamanho do recém- nascido. São Paulo, 1979. [Tese de Doutorado - Faculdade de Saúde Pública - USP].

Siqueira AAF de, Junior CC, Marcondes de Almeida PA, Tanaka AC d'A, Montelone PPR, Gonçalves de Arruda J, et al. Influencia da altura e ganho de peso maternos e da idade gestacional sobre o peso do recém-nascido: Estudo de 3 grupos de gestantes normais. Rev. Saúde Pública 1975; (9): $331-342$

Tanaka AC d'A Obesidade e Gravidez. São Paulo, 1980. [Tese de Mestrado - Faculdade de Saúde Pública - USP].

Smith CA. Effects of maternal nutrition upon the newborn infant in Holland (1944-1945). J.Pediatr 1947; 30: 229-43.

Tibrewala S, Shah $\mathrm{K}$. The use of arm circumference as an indicator of body weight in adult women. Baroda J. Nutr 1978; 5: 43-45.

World Health Organization. Predicting pre-pregnancy weight based on arm circumference. In: Phisical status: The use and interpretation of anthropometry. Geneva, 1995 (Who Technical Report Series, $N^{\circ} 854$ ) 
Wiley AS Neonatal size and infant mortality at high altitude in the westem Himalaya. Am. J. Phys. Anthropol 1994; 94(3): 289-305

Winikoff B, Debrovner C. Anthropometric determinants of birth weight. Obstet. Gynecol 1981; (58): 678-684.

Winick M. Malnutrition and brain development. New York 1976, Oxford University Press.

Zerfas A. A method to assess measurement performance with special emphasis on anthropometry. Los Angeles [ Ph. D. Thesis - University of California] 1985. 
ANEXOS 


\section{ANEXOS}

ANEXO 1.- LISTA DO PB, INDICE, ESTATURA DAS GESTANTES E PESO DO RECÉM NASCIDO ${ }^{A-1}$

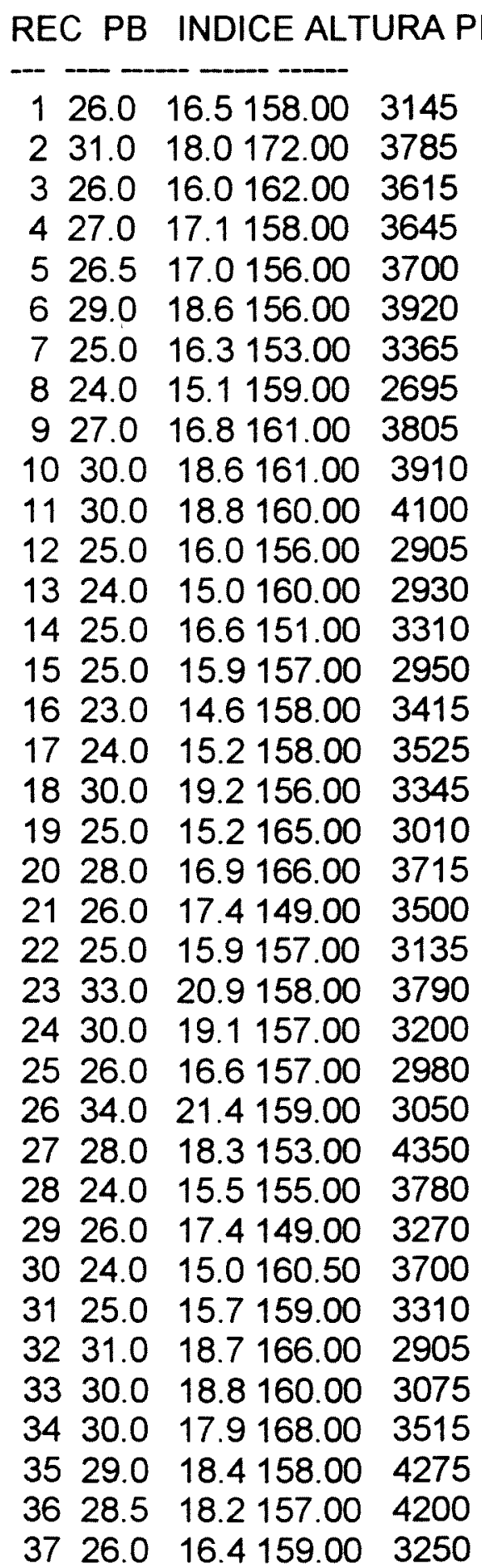

A -1 Anexos 


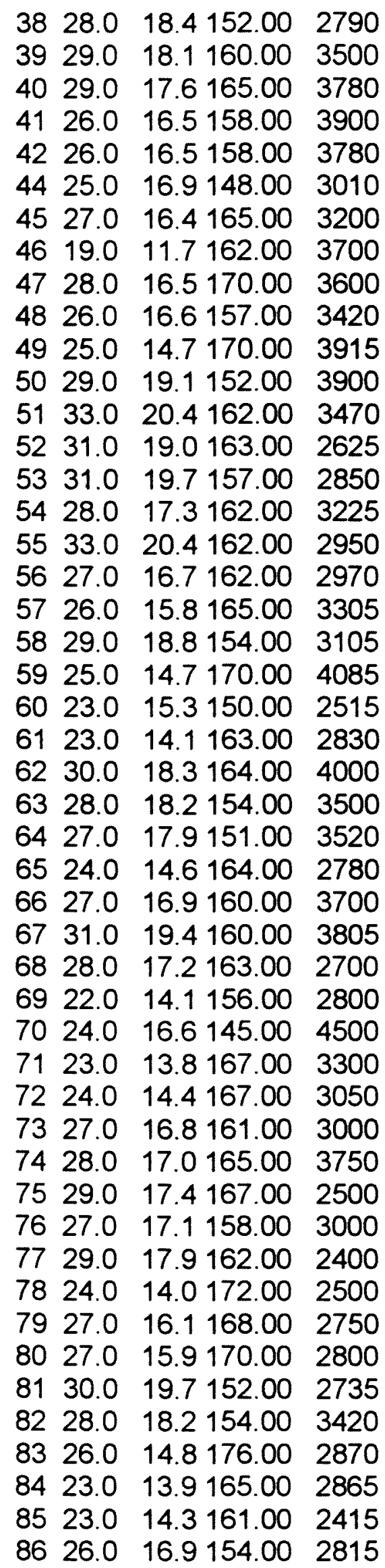




\begin{tabular}{|c|c|c|}
\hline 722.0 & & \\
\hline 828.0 & 68.00 & 15 \\
\hline 931.0 & & \\
\hline 9029.0 & & \\
\hline 126.0 & 15.6167 .00 & \\
\hline & 15.5161 .00 & \\
\hline & 57.00 & \\
\hline & & \\
\hline & & \\
\hline & & \\
\hline & & \\
\hline & & \\
\hline & & \\
\hline & & \\
\hline & & \\
\hline & & \\
\hline . & 18 & \\
\hline & & \\
\hline & & \\
\hline 36 & & \\
\hline & & \\
\hline $08<4$ & 15 & \\
\hline & & \\
\hline & & \\
\hline & & \\
\hline 240 & 15 & \\
\hline 1324.0 & 57.00 & \\
\hline & & \\
\hline & & \\
\hline & & \\
\hline 17 & & \\
\hline & & \\
\hline 24.0 & 0.00 & \\
\hline & & \\
\hline & 2.00 & \\
\hline & & \\
\hline & 2.00 & \\
\hline 1243 & 24.00 & \\
\hline & 2.00 & \\
\hline & & \\
\hline & & \\
\hline 12824.5 & 155.00 & 268 \\
\hline & 154.00 & 32 \\
\hline & 2.00 & \\
\hline & & \\
\hline & & \\
\hline & 18.8151 .00 & \\
\hline & 17.4152 .00 & \\
\hline
\end{tabular}




$$
\|
$$




\begin{tabular}{|c|c|c|c|}
\hline & & & \\
\hline & & & \\
\hline & & & \\
\hline & & & \\
\hline & & & \\
\hline & & 16.7156. & \\
\hline & & 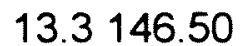 & \\
\hline & & & \\
\hline & & & \\
\hline & & 16.8155 & \\
\hline & & 17.7155 .00 & \\
\hline & & 22.1163 .00 & \\
\hline & & & \\
\hline & & & \\
\hline & & & \\
\hline & & & \\
\hline & & 57.00 & \\
\hline & & 21. & \\
\hline & & & \\
\hline & & & \\
\hline & & & \\
\hline & & 13.1156 .00 & \\
\hline & 2 & 14. & 210 \\
\hline & & & \\
\hline & & & \\
\hline & & 19. & \\
\hline & & 17. & 254 \\
\hline & & 17 & 35 \\
\hline & & & \\
\hline & & & \\
\hline & & & \\
\hline & & & \\
\hline & & 15 & \\
\hline & & & 327 \\
\hline & & & \\
\hline & & & \\
\hline & & & \\
\hline & & 15 & $26 ؟$ \\
\hline & & 15 & 273 \\
\hline & & & \\
\hline & & & 320 \\
\hline & & 21.11 & 290 \\
\hline & & 21.4 & 340 \\
\hline & & & 392 \\
\hline & & 18.11 & 286 \\
\hline & & & \\
\hline & & 17.1170 .00 & \\
\hline & & 19.6160 .0 & \\
\hline
\end{tabular}

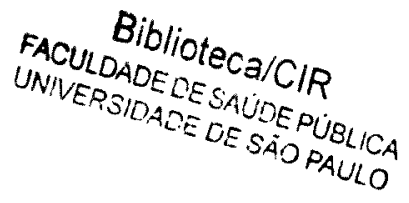




\begin{tabular}{|c|c|c|c|}
\hline & 26 & & \\
\hline & 27.6 & 9.00 & \\
\hline & 22 & 14.0 & \\
\hline & & & \\
\hline & & 16.5164 & \\
\hline & & & \\
\hline & 25.0 & 15.71 & \\
\hline & & & \\
\hline & & & \\
\hline & & & \\
\hline & 22. & 13 & \\
\hline & 27. & & \\
\hline & & & \\
\hline & 27 & & \\
\hline & & & \\
\hline & & & \\
\hline & 23. & & \\
\hline & 25 & & \\
\hline & & & \\
\hline & & & \\
\hline & & & \\
\hline & 20 & & 29 \\
\hline & 25.0 & 16 & 27 \\
\hline & & & \\
\hline & & & \\
\hline & & 15 & \\
\hline & 27.0 & & \\
\hline & 25 & & \\
\hline & & & \\
\hline & & & \\
\hline & & 15 & \\
\hline & & & \\
\hline & 26.5 & & 32 \\
\hline & 25.1 & & 324 \\
\hline & 28. & & \\
\hline & & & \\
\hline & & & \\
\hline & & & 49 \\
\hline & 27.0 & 16 & 335 \\
\hline & & & \\
\hline & & & \\
\hline & 28 & 18 & \\
\hline & & & \\
\hline & & & 30 \\
\hline & & & \\
\hline & & & \\
\hline & & 158.0 & \\
\hline & & & \\
\hline
\end{tabular}



$\begin{array}{lllll}327 & 23.4 & 14.0 & 167.00 & 2286 \\ 328 & 29.2 & 17.3 & 169.00 & 3105 \\ 329 & 28.0 & 19.0 & 147.00 & 3715 \\ 330 & 24.7 & 16.4 & 151.00 & 3365 \\ 331 & 29.0 & 19.2 & 151.00 & 3780 \\ 332 & 21.8 & 15.5 & 141.00 & 2905 \\ 333 & 28.2 & 17.6 & 160.00 & 2880 \\ 334 & 26.7 & 17.8 & 150.00 & 3420 \\ 335 & 27.8 & 17.6 & 158.00 & 3710 \\ 336 & 21.2 & 14.1 & 150.00 & 2670 \\ 337 & 28.6 & 17.5 & 163.00 & 3040 \\ 338 & 26.2 & 17.5 & 150.00 & 2980 \\ 339 & 29.3 & 18.3 & 160.00 & 3780 \\ 340 & 20.3 & 13.4 & 151.00 & 2780 \\ 341 & 28.0 & 18.1 & 155.00 & 3120 \\ 342 & 35.5 & 21.1 & 168.00 & 4050 \\ 343 & 28.5 & 18.4 & 155.00 & 2500 \\ 344 & 23.5 & 14.8 & 159.00 & 2830 \\ 345 & 28.0 & 17.6 & 159.00 & 4350 \\ 346 & 28.8 & 18.7 & 154.00 & 2790 \\ 347 & 24.5 & 15.8 & 155.00 & 2730 \\ 348 & 32.2 & 19.5 & 165.00 & 3000 \\ 349 & 28.5 & 17.7 & 161.00 & 3750 \\ 350 & 25.4 & 16.3 & 156.00 & 2550 \\ 351 & 26.0 & 16.3 & 160.00 & 3250\end{array}$ 
ANEXO 2.- INDICE<16 E OS CORRESPONDENTES PERIMETROS A-9 BRAQUIAIS E ESTATURA DA GESTANTE, ASSIM COMO O PESO DOS RECÉM-NASCIDOS, CONSIDERADOS COM PESO INADEQUADO.

REC PB. INDICE ALTURA PESORN

\begin{tabular}{|c|c|c|}
\hline & & \\
\hline & & \\
\hline & 50.00 & \\
\hline & $\$ 3.00$ & 830 \\
\hline & & \\
\hline 22.0 & & \\
\hline 24.0 & & 2 \\
\hline 27.0 & .00 & 275 \\
\hline 27.0 & .00 & 2800 \\
\hline 26.0 & .00 & 2870 \\
\hline 23.0 & & \\
\hline 23.0 & .00 & 2415 \\
\hline 22.0 & .00 & 2905 \\
\hline 22.0 & .50 & 2050 \\
\hline 23.0 & .00 & 2 \\
\hline 126.0 & .00 & 2650 \\
\hline 24.0 & & \\
\hline 22.0 & 4.00 & 2860 \\
\hline 24.0 & 15 & 272 \\
\hline 23.0 & 15 & 2750 \\
\hline 23.0 & 00 & 2700 \\
\hline 24.3 & .00 & 2730 \\
\hline 24.5 & .00 & 2680 \\
\hline 22.0 & & 265 \\
\hline 20.5 & 12. & 250 \\
\hline 23.0 & & 260 \\
\hline & & \\
\hline 21.0 & .00 & 2670 \\
\hline 24.5 & 15.3 & 2820 \\
\hline 23.0 & 14 & 251 \\
\hline 23.5 & 14 & 2410 \\
\hline 22.5 & 3.00 & 2100 \\
\hline 24.5 & $14.7^{\circ}$ & 269 \\
\hline 24.3 & 15.2 & 2695 \\
\hline & & 285 \\
\hline 22.0 & 14.2 & 286 \\
\hline & & 278 \\
\hline 24.0 & 14.4167 .00 & 269 \\
\hline 25.0 & 15.8158 .50 & \\
\hline
\end{tabular}

A - 9 Anexos 


$$
\begin{array}{lllll}
204 & 20.5 & 13.1 & 156.00 & 2670 \\
205 & 22.2 & 14.2 & 156.00 & 2100 \\
212 & 25.0 & 15.4 & 162.00 & 2630 \\
213 & 22.7 & 14.3 & 159.00 & 2510 \\
220 & 24.0 & 15.3 & 157.00 & 2695 \\
221 & 24.3 & 15.1 & 161.00 & 2730 \\
222 & 24.0 & 15.0 & 160.00 & 2600 \\
228 & 21.8 & 14.1 & 155.00 & 2660 \\
237 & 25.0 & 15.7 & 159.00 & 2500 \\
239 & 23.0 & 15.5 & 148.50 & 2510 \\
240 & 25.0 & 15.8 & 158.00 & 2865 \\
247 & 23.3 & 14.1 & 165.50 & 2620 \\
251 & 21.0 & 13.3 & 158.00 & 2680 \\
254 & 23.5 & 14.4 & 163.00 & 2250 \\
255 & 24.3 & 15.6 & 156.00 & 2730 \\
259 & 21.5 & 14.5 & 148.00 & 2670 \\
262 & 20.0 & 13.5 & 148.00 & 2920 \\
267 & 23.8 & 15.3 & 156.00 & 2870 \\
281 & 23.5 & 14.6 & 161.00 & 2415 \\
284 & 23.4 & 15.1 & 155.00 & 2615 \\
292 & 23.6 & 16.0 & 147.50 & 2800 \\
296 & 25.3 & 16.0 & 158.00 & 2540 \\
297 & 23.6 & 15.0 & 157.50 & 2870 \\
300 & 23.5 & 15.7 & 150.00 & 2515 \\
309 & 24.5 & 14.7 & 167.00 & 2700 \\
310 & 23.5 & 15.8 & 149.00 & 2615 \\
314 & 21.2 & 13.5 & 156.50 & 2670 \\
317 & 22.0 & 13.8 & 159.00 & 2800 \\
327 & 23.4 & 14.0 & 167.00 & 2286 \\
332 & 21.8 & 15.5 & 141.00 & 2905 \\
336 & 21.2 & 14.1 & 150.00 & 2670 \\
340 & 20.3 & 13.4 & 151.00 & 2780 \\
344 & 23.5 & 14.8 & 159.00 & 2830 \\
347 & 24.5 & 15.8 & 155.00 & 2730
\end{array}
$$




\section{ANEXO 3.- LISTA DO PB CORRESPONDENTES AOS DIFERENTES INDICES E A ESTATURA DA GESTANTE ${ }^{A-11}$}

\begin{tabular}{|c|c|c|c|c|}
\hline $\begin{array}{r}\text { Indice } \\
<16\end{array}$ & Indice $<14$ & $\begin{array}{r}\text { Indice } \\
<12\end{array}$ & & Indice $=17$ \\
\hline LEVE & MODERADO & GRAVE & $\begin{array}{l}\text { Estatur } \\
\text { a }\end{array}$ & $\begin{array}{r}\text { PB } \\
\text { NORMAL }\end{array}$ \\
\hline 22,2 & 19,4 & 16,6 & 138,7 & 23,5 \\
\hline 22,5 & 19,7 & 16,9 & 140,6 & 24 \\
\hline 22,9 & 20 & 17 & 143,1 & 24,3 \\
\hline 23,2 & 20,3 & 17,4 & 145 & 24,7 \\
\hline 23,5 & 20,6 & 17,6 & 146,9 & 25 \\
\hline 23,6 & 20,6 & 18 & 147,5 & 25 \\
\hline 24 & 21 & 18 & 150 & 25,5 \\
\hline 24,4 & 21,4 & 18,3 & 152,5 & 26 \\
\hline 24,5 & 21,4 & 18,4 & 153,1 & 26 \\
\hline 24,7 & 21,6 & 18,5 & 154,3 & 26,2 \\
\hline 25,2 & 21,7 & 18.6 & 155 & 26,4 \\
\hline 25,2 & 22 & 18,9 & 157,5 & 26,8 \\
\hline 25,4 & 22,2 & 19 & 158,7 & 27 \\
\hline 25,5 & 22,3 & 19,1 & 159,3 & 27 \\
\hline 25,8 & 22,6 & 19,3 & 161,2 & 27,4 \\
\hline 26,2 & 22,9 & 19,6 & 163,7 & 27,8 \\
\hline 26.3 & 23 & 19.7 & 164,3 & 28 \\
\hline 26,4 & 23,1 & 19,8 & 165 & 28 \\
\hline 26,6 & 23,3 & 19,9 & 166,2 & 28,2 \\
\hline 26,8 & 23,5 & 20,1 & 167,5 & 28,4 \\
\hline 27,2 & 23,8 & 20,4 & 170 & 29 \\
\hline 27,4 & 23,9 & 20,5 & 171,2 & 29 \\
\hline 27,4 & 24,2 & 20,7 & 173,1 & 29,4 \\
\hline 28,5 & 24,9 & 21,4 & 178,1 & 30 \\
\hline 28,6 & 25 & 21,4 & 178,7 & 30,4 \\
\hline 29 & 25,4 & 21,7 & 181,2 & 31 \\
\hline 29,2 & 25,5 & 21,9 & 182,5 & 31 \\
\hline 29,4 & 25,7 & 22 & 183,7 & 31,2 \\
\hline 29,7 & 25,9 & 22,3 & 185,6 & 31,6 \\
\hline 30,1 & 26,3 & 22,6 & 188,1 & 32 \\
\hline
\end{tabular}


ANEXO 4.- EXPRESSÀO MATEMATICA DAS CURVAS DO INDICE NOS DIFERENTES GRAUS ${ }^{A-12}$

INDICE < 16 -SATURATION GROWTH MODEL

$Y=a x / b+x$

Onde $Y=$ indice $<16$

$$
\begin{aligned}
& a=-32322.028 \\
& b=-5199.3041 \\
& s=0.58287561 \\
& r=0.99919385
\end{aligned}
$$

INDICE < 14 - HOERL MODEL

$$
Y=a b^{x} x^{c}
$$

Onde $Y=$ indice $<14$

$$
\begin{aligned}
& a=8.806056 \\
& b=1.0045766 \\
& c=0.8997758 \\
& s=0.2309972 \\
& r=0.999987
\end{aligned}
$$

INDICE $<12$ - MODEL RATIONAL FUNCTION

$$
Y=a+b x / 1+c x+d x^{2}
$$

Onde $Y=$ indice $<12$

$$
\begin{aligned}
& a=58.21565 \\
& b=-0.67352228 \\
& c=-0.055461219 \\
& d=0.0094349016 \\
& s=0.5777283 \\
& r=0.9992646
\end{aligned}
$$




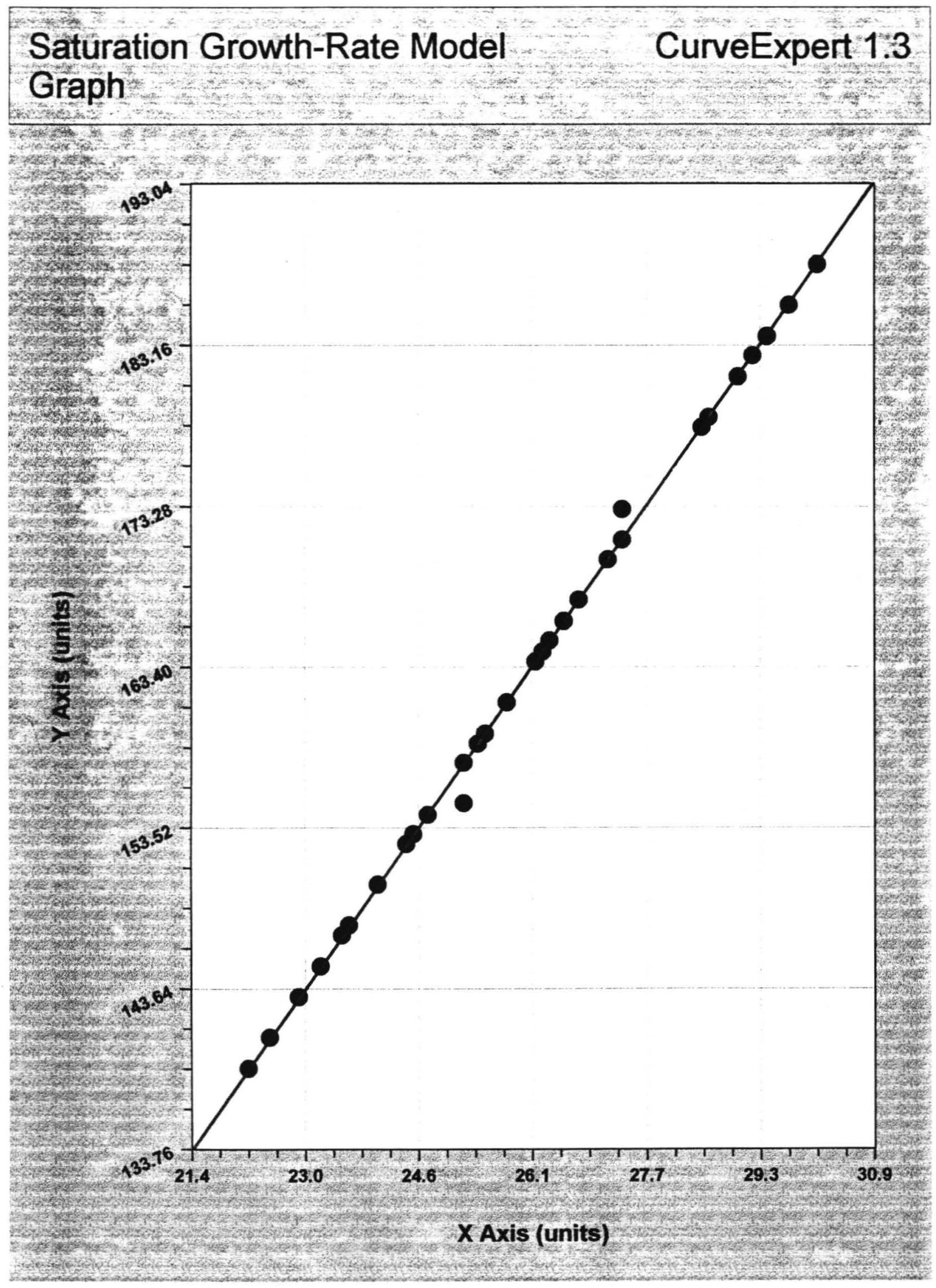




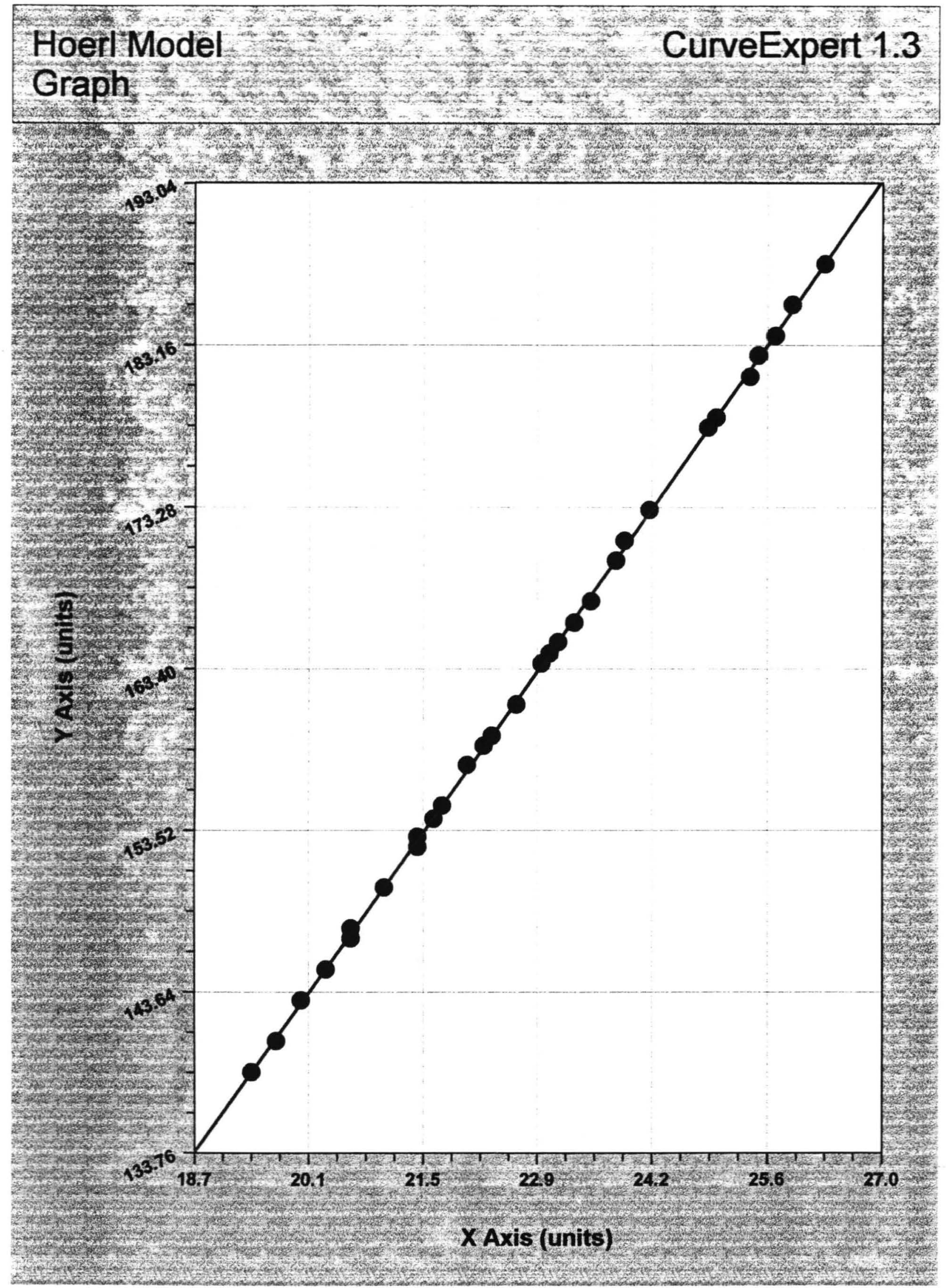




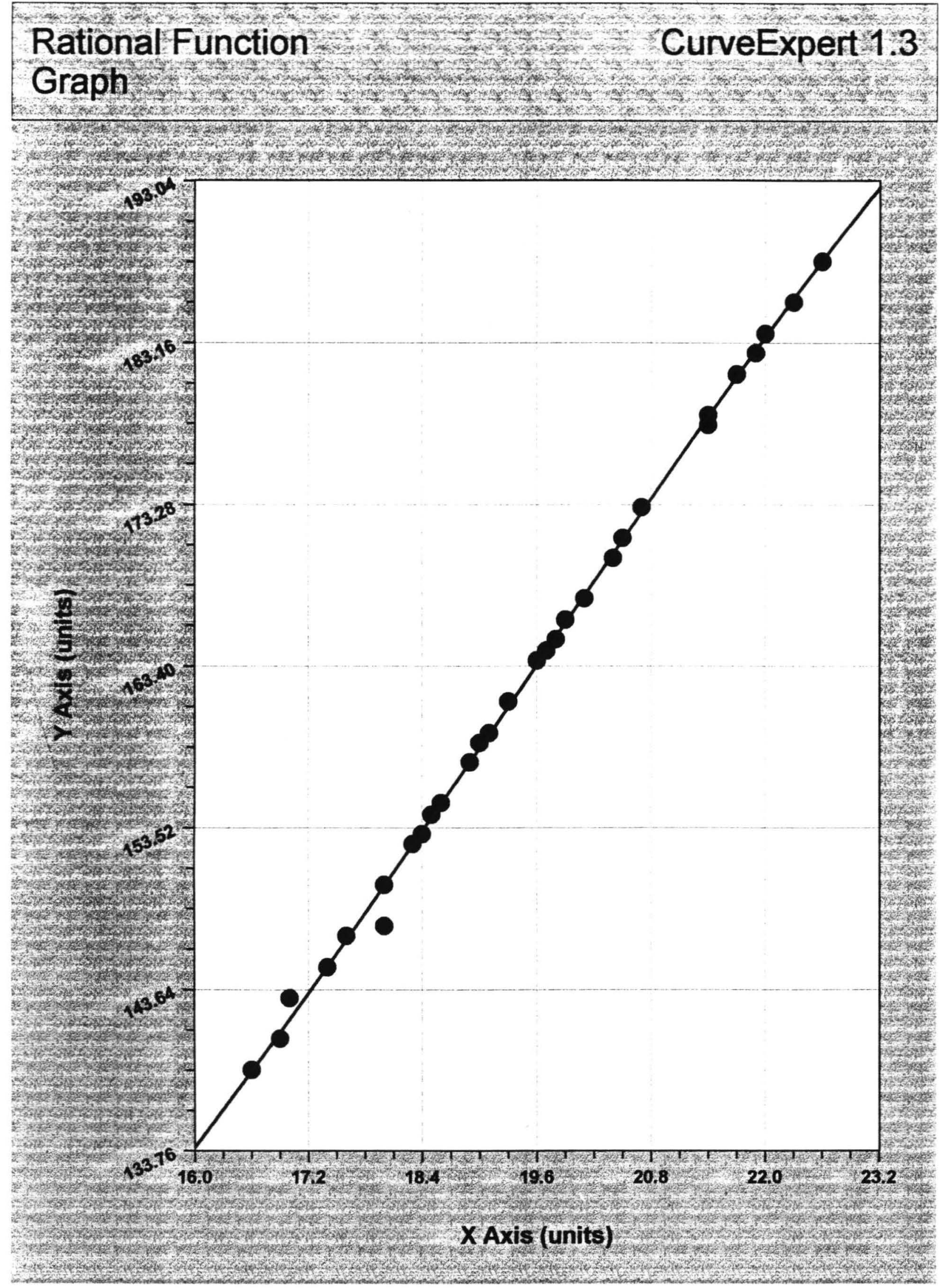


Anexo 5.- Questionário utilizado para a coleta de dados ${ }^{\mathrm{A}-13}$

Pesquisa: Perímetro braquial da gestante e sua relação com o peso pré-gestacional e o peso do recém-nascido ${ }^{1}$

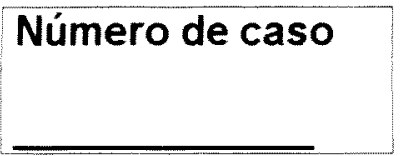

\section{TRIMESTRE DA GESTAÇÃO}

I $\square \quad$ II $\square$ III

Data da consulta:

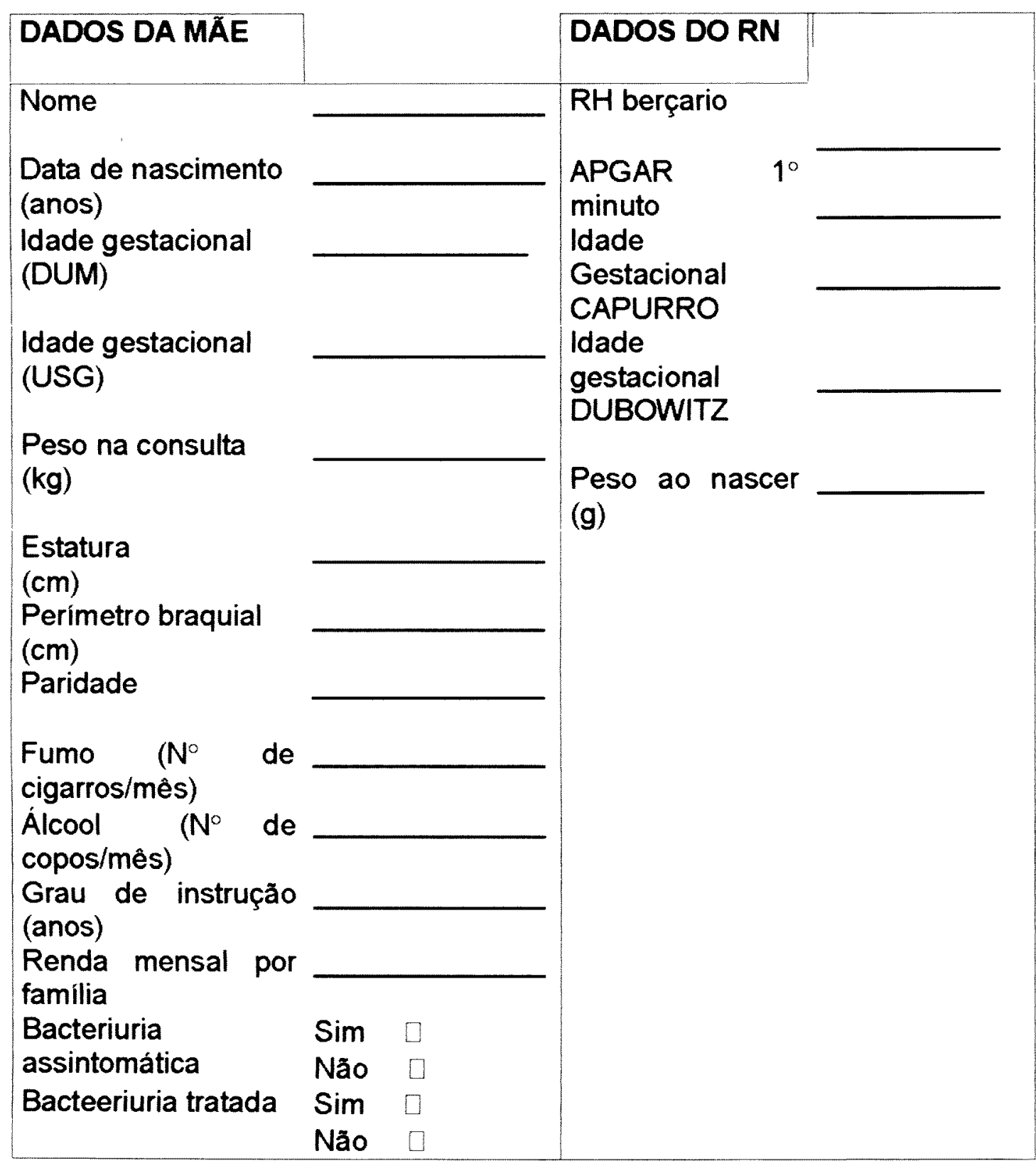

\footnotetext{
Anexos

Responsavel Anamania E. Ricalde de Freixa - Departamento de Saude Matemo-Infantil - FSP-USP, 1097
} 